\title{
The application of GPR and ERI in combination with exposure logging and retrodeformation analysis to characterize sinkholes and reconstruct their impact on fluvial sedimentation
}

Mario Zarroca, ${ }^{1 *}$ Xavier Comas, ${ }^{2}$ Francisco Gutiérrez, ${ }^{3}$ Domingo Carbonel, ${ }^{3}$ Rogelio Linares, ${ }^{1}$ Carles Roqué, ${ }^{4}$ Morteza Mozafari, ${ }^{5}$ Jesús Guerrero $^{3}$ and Xavier M. Pellicer ${ }^{6}$

${ }^{1}$ Department of Geology, Autonomous University of Barcelona, Bellaterra, Barcelona, Spain

${ }^{2}$ Department of Geosciences, Florida Atlantic University, Davie, FL USA

${ }^{3}$ Departamento de Ciencias de la Tierra, Universidad de Zaragoza, Zaragoza, Spain

4 Àrea de Geodinàmica Externa i Geomorfologia, Universitat de Girona, Girona, Spain

${ }^{5}$ Department of Earth Sciences, Shiraz University, Iran

${ }^{6}$ Geological Survey of Ireland, Dublin, Ireland

*Correspondence to: Mario Zarroca, Serra Húnter Fellow, Department of Geology, Autonomous University of Barcelona, Bellaterra, Barcelona, Spain. E-mail: mario. zarroca.hernandez@uab.cat

\begin{abstract}
This work illustrates the practicality of investigating sinkholes integrating data gathered by ground penetrating radar $(\mathrm{GPR})$, electrical resistivity imaging (ERI) and trenching or direct logging of the subsidence-affected sediments in combination with retrodeformation analysis. This mutidisciplinary approach has been tested in a large paleosinkhole developed during the deposition of a Quaternary terrace on salt-bearing evaporites. The subsidence structure, exposed in an artificial excavation, is located next to Puilatos, a village that was abandoned in the 1970s due to severe subsidence damage. Detailed logging of the exposure revealed that the subsidence structure corresponds to an asymmetric sagging and collapse paleosinkhole with no clear evidence of recent activity. The sedimentological and structural relationships together with the retrodeformation analysis indicate that synsedimentary subsidence controlled channel location, the development of a palustrine environment and local changes in the channel pattern. GPR profiles were acquired using an array of systems with different antenna frequencies, including some recently developed shielded antennas with improved vertical resolution and penetration depth. Although radargrams imaged the faulted sagging structure and provided valuable data on fault throw, they did not satisfactorily image the complex architecture of the fluvial deposit. ERI showed lower resolution but higher penetration depth when compared to GPR, roughly capturing the subsidence structure and yielding information on the thickness of the high-resistivity alluvium and the nature of the underlying low-resistivity karstic residue developed on top of the halite-bearing evaporitic bedrock. Data comparison allows the assessment of the advantages and limitations of these complementary techniques, highly useful for site-specific sinkhole risk management.
\end{abstract}

KEYWORDS: evaporite karst; near-surface geophysics; trenching; sagging sinkhole; Ebro Valley (northeast Spain)

\section{Introduction}

Ground subsidence associated with sinkhole activity constitutes a significant hazard with an increasing societal and economic impact in numerous regions worldwide (e.g. Gutiérrez et al., 2014). An essential aspect for effective risk mitigation is the precise mapping and characterization of the existing sinkholes, since damage is frequently related to concealed karst depressions buried by natural or man-made deposits (Galve et al., 2009; Carbonel et al., 2014, 2015). Most investigations dealing with sinkhole characterization using subsurface methods have focussed on collapse sinkholes underlain by cavernous carbonate bedrock, and utilize near-surface geophysical methods in combination with geotechnical boreholes (van Schoor, 2002; Zhou et al., 2002; Kruse et al., 2006; Valois et al., 2011; Festa et al., 2012; Nouioua et al., 2013; Youssef et al., 2013). However, large sagging sinkholes related to evaporite dissolution have been barely explored and the trenching technique (or exposure logging) has been applied in very few sinkhole investigations (e.g. Carbonel et al., 2014, and references cited therein).

Subsidence phenomena related to evaporite dissolution have distinctive features when compared to those occurring in carbonate karst, where bedrock solubility is substantially lower (Gutiérrez and Cooper, 2013): (1) Sagging is a common subsidence mechanism that may produce large enclosed 
depressions affected by gradual settlement; (2) karstification may involve highly soluble salts, resulting in rapid subsidence rates over long time spans; (3) long-sustained ground subsidence may interact with depositional environments, leading to thickenings and controlling the dynamics and characteristics of morpho-sedimentary systems (e.g. Guerrero et al., 2008); (4) dissolution may affect thick evaporitic units generating a peculiar stratigraphy, including substantial karstic residues frequently misinterpreted as primary stratigraphic units.

This work aims at investigating the impact of dissolutioninduced subsidence phenomena on fluvial sedimentation in the Gállego Valley, northeast Spain, were all the peculiar evaporite karst features indicated earlier concur. It also aims at stressing the practicality of characterizing hazardous sinkholes integrating data gathered by near-surface geophysical techniques and trenching or direct logging of the subsidenceaffected sediments in combination with retrodeformation analysis. The application and comparison of the different methods allow assessing their advantages and limitations, as well as their complementariness. To meet these goals we analyse a large synsedimentary sagging sinkhole affecting terrace deposits in an area where sinkhole activity has a particularly significant detrimental impact: (1) abandonment of Puilatos village due to subsidence damage next to the investigation site (Benito and Gutiérrez, 1988; Gutiérrez and Gutiérrez, 1998);
(2) continuous rapid subsidence in two nearby major roads; and (3) recent occurrence of a catastrophic collapse sinkhole next to the Zaragoza-Huesca high-speed railway. The partially exposed subsidence structure is analysed using three methods: direct exposure logging in combination with retrodeformation analysis, ground penetrating radar (GPR), including newly developed high dynamic range (HDR) antennas, and electrical resistivity imaging (ERI). The work illustrates how the integration of data gathered through these complementary techniques may provide valuable information on the distribution and geometry of sinkholes, subsidence mechanisms, their deformational history, and the impact of subsidence on fluvial sedimentation and dynamics.

\section{Geological and Geomorphological Setting}

The study area is located in the lower reach of the Gállego River valley, a Pyrenean tributary of the Ebro River in northeast Spain (Figure 1A). The Gállego River, around 215 km long, has a catchment area of approximately $4000 \mathrm{~km}^{2}$ and an average annual flow volume of $1200 \times 10^{6} \mathrm{~m}^{3}$. The analysed subsidence structure affects a Pleistocene terrace of the Gállego River situated next to Puilatos (Figures 1 and 2).

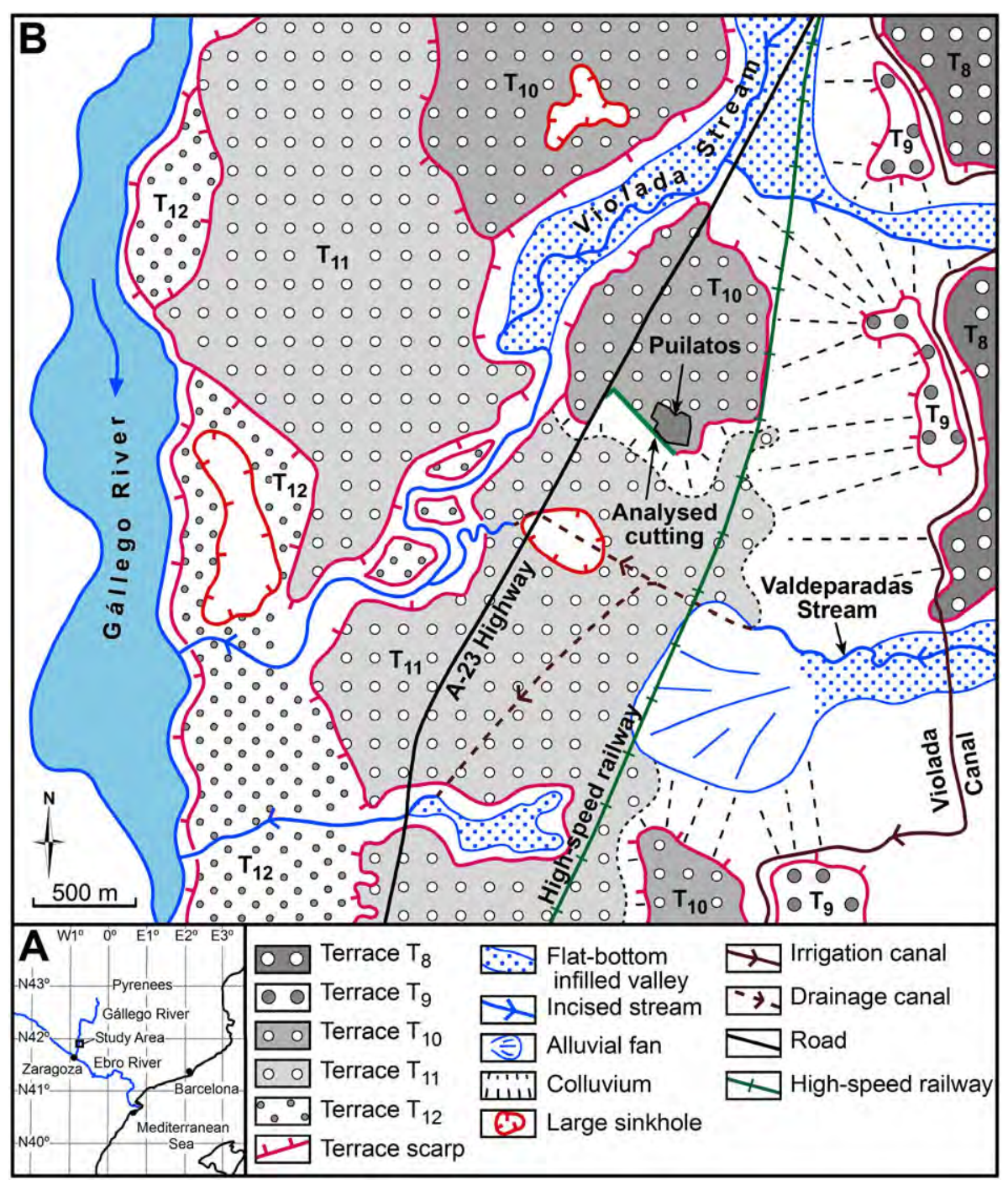

Figure 1. Location of the study area. (A) General geographic setting. (B) Sketch showing the geomorphological context of the analysed artificial cutting excavated in the Gállego River terrace $\mathrm{T}_{10}$. The exposure is located just next to Puilatos village, which was completely demolished due to severe subsidence damage. The large subsidence depression to the south is traversed by the adjacent N-330 motorway and the A-23 highway (the latter not shown) as well as an artificial drainage canal. [Colour figure can be viewed at wileyonlinelibrary.com] 

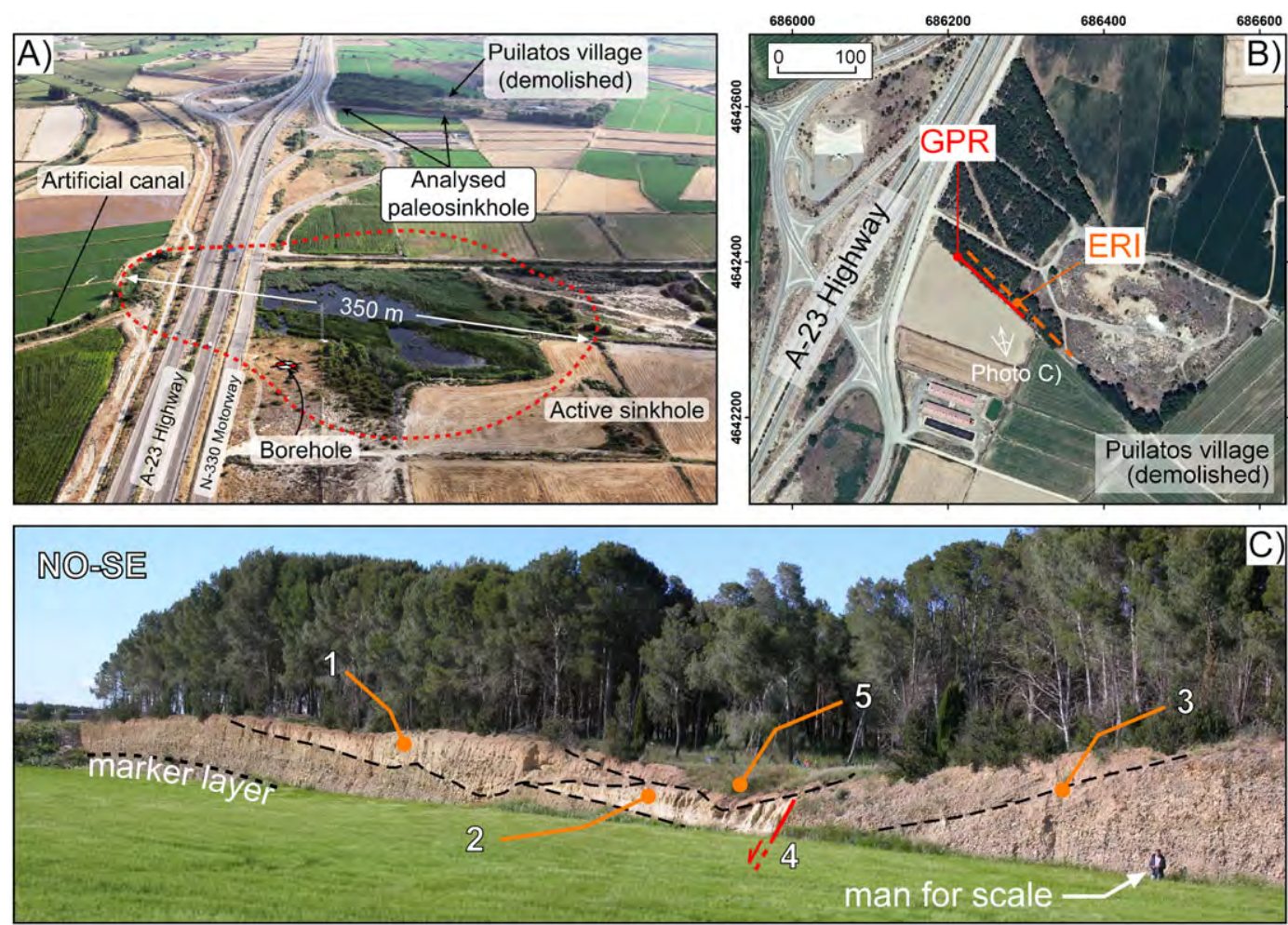

Figure 2. (A) Oblique aerial photograph showing the analysed section next to the Puilatos village (background) and the large active sinkhole that affects the A-23 highway, the N-330 motorway and an artificial canal (foreground). (B) Layout of the ground penetrating radar (red solid line) and electrical resistivity imaging (orange dashed line) profiles, over the logged exposure (aerial photograph PNOA from the Spanish National Geographic Institute, Datum 30T ETRS89). (C) Photograph of the logged artificial exposure showing a sagging and collapse paleosinkhole affecting the deposits of the Gállego River terrace $\mathrm{T}_{10}$. 1, Sand-dominated channel; 2, palustrine facies (pounded sinkhole); 3, edge of gravel channel; 4, collapse fault truncated by man-made fill; 5, man-made fill. [Colour figure can be viewed at wileyonlinelibrary.com]

From a geological perspective, the site is located in the central part of the Ebro Cenozoic Basin. Here, the bedrock corresponds to the Oligo-Miocene Zaragoza Gypsum Formation, deposited in an extensive high-salinity playa-lake (Quirantes, 1978; Salvany et al., 2007). This formation has a subhorizontal structure and reaches several hundred metres in thickness. In the subsurface, it consists of anhydrite $\left(\mathrm{CaSO}_{4}\right)$, halite $(\mathrm{NaCl})$, and glauberite $\left(\mathrm{Na}_{2} \mathrm{Ca}\left[\mathrm{SO}_{4}\right]_{2}\right)$, with interlayered clays and marls. The best available data on the lithostratigraphic composition of the evaporites have been obtained by mining exploration boreholes drilled in the surroundings of Zaragoza city, 40 $\mathrm{km}$ southwards from the studied outcrop. These data reveal: (1) a 75-m-thick halite unit situated between 175 and $100 \mathrm{~m}$ above sea level (a.s.I.) (the analysed outcrop lies at approximately 300 m a.s.l.; Salvany, 2009); and (2) glauberite units as much as $30 \mathrm{~m}$ thick within a sequence that extends from 260 to $175 \mathrm{~m}$ a.s.I. In outcrop, the Zaragoza Formation displays secondary gypsum $\left(\mathrm{CaSO}_{4} \cdot 2 \mathrm{H}_{2} \mathrm{O}\right)$ derived from the replacement of glauberite (incongruent dissolution) and anhydrite (hydration). This secondary gypsum, up to $120 \mathrm{~m}$ thick, grades to glauberite and anhydrite towards the unweathered inner and deeper part of the rock massif (Salvany, 2009). An oil exploration borehole (Martón) drilled around $10 \mathrm{~km}$ southwest of Puilatos indicates the presence of a halite member between 142 and $12 \mathrm{~m}$ a.s.I., consisting of bedded halite with subordinate marls and nodular anhydrite (Torrescusa and Klimowitz, 1990).

Around $500 \mathrm{~m}$ south of the analysed exposure, there is a $c$. $400 \mathrm{~m}$ long active sinkhole that causes rapid sagging on the $\mathrm{N}-330$ motorway and the adjacent A-23 Zaragoza-Huesca highway (Figures 1 and 2). It has also induced local gradient reversals in an artificial drainage connected to the Valdeparadas Stream (Figure 2). The high subsidence rate in this sinkhole, in the order of centimetres per year $\left(\mathrm{cm} \mathrm{yr}^{-1}\right)$, suggests rapid salt dissolution. A geotechnical borehole drilled within the sinkhole (see location in Figure 2B) penetrated a gravelly Quaternary cover $4 \mathrm{~m}$ thick, underlain by a dark marly clay around $47 \mathrm{~m}$ thick attributable to a karstic residue. This residual material includes: (1) bodies of Quaternary gravel more than $2 \mathrm{~m}$ thick embedded within the karstic residue at $17 \mathrm{~m}$ below the surface, corresponding to the infill of voids; (2) fragments of halite within the residual clay from $42 \mathrm{~m}$ depth; (3) centimetre- to decimetre-thick halite beds below $51 \mathrm{~m}$ depth. These features suggest interstratal dissolution of haliterich evaporitic bedrock, probably related to focussed groundwater discharge (e.g. Guerrero et al., 2013).

Based on detailed geomorphological mapping, Benito et al. (1998) differentiated 12 terrace levels in the lower reach of the Gállego River, with the oldest level situated at around 175 $\mathrm{m}$ above the present-day channel. Upstream of the Zuera village, including the investigated area, the terrace deposits have a limited thickness and are inset into bedrock. Downstream of Zuera, some terraces show thickened deposits that fill an evaporite dissolution-induced basin $30 \mathrm{~km}$ long and $8 \mathrm{~km}$ wide, where the alluvium reaches $110 \mathrm{~m}$ in thickness and shows a highly irregular contact with the evaporitic bedrock. The studied deformed alluvium corresponds to terrace $T_{10}$, situated in our investigation site at $26 \mathrm{~m}$ above the current channel. Here, Benito et al. (2010) obtained an optically stimulated luminescence (OSL) age of $124 \pm 13$ ka (considering an error margin of one time the standard deviation) from a sample collected in a sand-filled channel. This is an apparently very old date for a terrace situated $26 \mathrm{~m}$ above the channel, suggesting an anomalously low long-term entrenchment rate of 0.2 $\mathrm{mm} \mathrm{yr}^{-1}$. In Biscarrués, around $35 \mathrm{~km}$ north of Puilatos, the terrace of the Gállego River situated at c. $35 \mathrm{~m}$ above the channel, has been dated by OSL at $45 \pm 3 \mathrm{ka}$ (Lewis et al., 2009), yielding a much higher entrenchment rate of $0.8 \mathrm{~mm} \mathrm{yr}^{-1}$. This 
apparent discrepancy could be related to contrasting incision patterns between the reaches underlain by insoluble bedrock and salt-bearing evaporites affected by long-sustained solution subsidence.

\section{Methods}

\section{Direct methods: exposure logging}

A $120 \mathrm{~m}$ long section of the artificial excavation showing the paleosinkhole was mapped at 1:50 scale after improving the 6-7 $\mathrm{m}$ high exposure by manually cleaning the outcrop (Figures 2 and 3). The stratigraphic and structural features were logged on graph paper with the aid of photomosaics, using as reference an orthogonal grid with a spacing of 1 or $2 \mathrm{~m}$. This is essentially the same procedure that has been applied in multiple active sinkholes in the Ebro Basin investigated via trenching (e.g. Gutiérrez et al., 2008a, 2009, 2011; Carbonel et al., 2014, 2015). The characterization of the sedimentological features was largely based on the lithofacies and architectural elements proposed by Miall $(1978,1985)$ for fluvial deposits.

\section{Indirect methods: geophysical survey}

The subsidence structure was explored by two near-surface geophysical techniques. The surveys were conducted in April 2013 and June 2014, and included parallel GPR common offset and ERI profiles acquired on the upper platform of the logged wall. The GPR and ERI lines were situated 3 and $8 \mathrm{~m}$ apart from the crest of the wall, respectively (Figure $2 \mathrm{C}$ ).

\section{Ground penetrating radar (GPR)}

GPR is a geophysical technique capable of imaging nearsurface features by measuring differences in electromagnetic properties of rocks and soils (van Dam and Schlager, 2000). GPR systems encompass a transmitting antenna that generates electromagnetic (EM) radio waves (typically in the 25 to 2000 $\mathrm{MHz}$ frequency range) that travel through the subsurface, a receiver antenna that captures the reflected EM wave signals, and a control unit that digitally records the time delay and strength of the signal. A radargram depicting a series of EM wave reflections with depth is constructed. Wave reflections are related to changes in the EM impedance due to variations in the physical properties of the subsurface material (i.e. dielectric permittivity, electrical conductivity and magnetic permeability). Distinctive reflections are related to sharp changes in the EM wave propagation velocity and energy attenuation. The EM wave velocity is mainly controlled by the dielectric permittivity of the rocks and water content, while the electrical bulk resistivity determines the wave energy attenuation. Both wave features are primarily controlled by the texture, porosity, moisture content and hydrochemistry of the materials (Urish, 1981; van Dam and Schlager, 2000). Thus, GPR can be a practical technique for imaging various features associated with sinkholes (e.g. cavities, sinkhole fills, collapse faults, fissures, sagging structures) (e.g. Carbonel et al., 2014, 2015; Rodríguez et al., 2014). Under favourable reflectivity conditions GPR has been also proved proficient for near-surface stratigraphic investigation (e.g. Neal, 2004; Pellicer et al., 2014). Differences in the reflection pattern can be used to define radar-facies as corresponding to different sedimentary facies (Smith and Jol, 1995; Neal et al., 2002; Neal, 2004). A significant drawback of GPR when compared to other near surface geophysical methods, such as ERI, is the limited investigation depth, especially in areas underlain by materials with high electrical conductivity (Davis and Annan, 1986).

GPR profiles were collected using two different systems: a RIS system (IDS Ingegneria dei Sistemi, Fareham) with a bistatic shielded $160 \mathrm{MHz}$ and unshielded $60 \mathrm{MHz}$ central frequency antennas, and a GroundExplorer (GX) system (by MAL $\AA$ Geosciences, Charleston, SC) with shielded HDR $160 \mathrm{MHz}$ antennas. While shielded antennas tend to minimize environmental noise during data acquisition, unshielded antennas allowed, in our case, increasing of depth of investigation (DOI). Furthermore, bistatic systems enable transmitter and receiver antennas to be separated and therefore surveys other than traditional common offsets (such as common midpoints) can be performed. The data were recorded at trace intervals between 0.1 and $0.2 \mathrm{~m}$ spacing by dragging the antenna directly on the soil surface in order to enhance ground contact and maximize depth of penetration. The use of different acquisition systems was aimed at investigating how different configuration settings, shielding and frequencies may influence imaging results. For example, although the two systems shared $160 \mathrm{MHz}$ shielded antennas, MAL $\AA^{\prime}$ 's newly developed HDR system is quite different to the more conventional RIS system, particularly because the former is based in real-time sampling technology resulting in significantly faster data acquisition rates. The newly designed antennas also provide enhanced

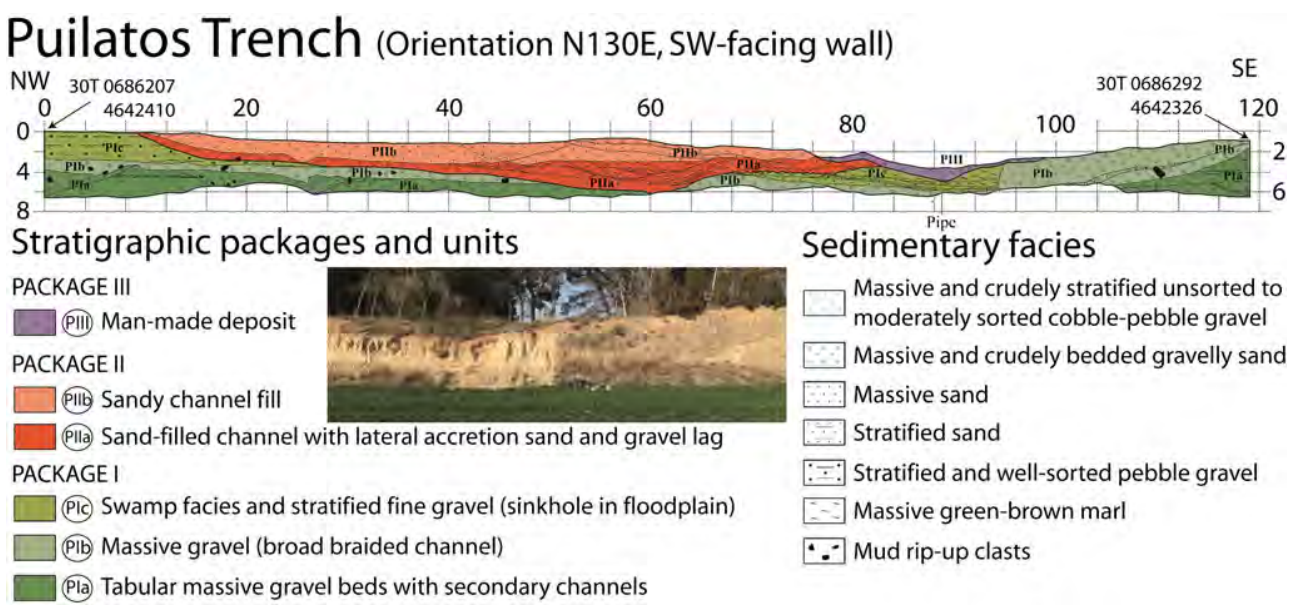

Figure 3. Log of the analysed artificial exposure showing the deposits of the terrace $\mathrm{T}_{10}$ of the Gállego River affected by a paleosinkhole. The inset image shows the portion of the excavation where swamp facies (unit PIc) are in fault contact with channel gravel facies (unit Plb). [Colour figure can be viewed at wileyonlinelibrary.com] 
signal-to-noise ratio when compared to conventional systems. Such improvement over conventional GPR systems allows the GX HDR system to deliver both higher resolution data and enhanced depth of penetration.

All GPR data were processed using ReflexW software (Sandmeier Scientific, Karlsruhe), and according to the following sequence: (i) a one-dimensional (1D)-dewow, to eliminate low frequencies by subtracting a mean amplitude calculated for each trace over a $17 \mathrm{~ns}$ and $6 \mathrm{~ns}$ when using $60 \mathrm{MHz}$ and $160 \mathrm{MHz}$ antennae respectively; (ii) a two-dimensional (2D)-background removal filter using a mean trace for entire 600 ns time window; (iii) a time-varying gain to distribute amplitudes equally in the time axis for each trace; (iv) a static correction, to eliminate the time delay between the signal triggering and recording; (v) a 1D-band pass frequency filter (with corner frequencies of 52,138, 177 and $230 \mathrm{MHz}$ for both 160 $\mathrm{MHz}$ antennas and 20,30, 83, and $138 \mathrm{MHz}$ for the $80 \mathrm{MHz}$ antenna), to eliminate high and low frequency noise; (vi) a topographic correction, to account for changes in terrain elevation; the profile of the ground surface was recorded by a Sprinter 100 digital level (Leica, Wetzlar); and (vii) a Kirchhoff migration based on a single velocity of $0.11 \mathrm{~m} \mathrm{~ns}^{-1}$, to collapse diffraction hyperbolas and remove distortions and dip displacements from reflections associated with the three-dimensional (3D) nature of signal radiation. The subsurface velocity was estimated from (1) common midpoint (CMP) surveys collected in the area using the RIS $160 \mathrm{MHz}$ shielded antennas [see Neal (2004) for further information on estimation of velocity from CMP surveys]; and (2) stratigraphic boundaries mapped in the underlying exposure and matched with the corresponding reflectors in the GPR common offset profiles. It should be noted the limitations of our migration when using a single velocity, potentially resulting in inaccurate placement of reflectors when correcting for reflector slopes. The migration performed used a weighted summation for each point along the profile over a pre-set number of traces that is determined from hyperbolas of pre-set bandwidth. We tested several summation widths (up to 60 traces) resulting in no relevant changes in the migrated profiles (Figure 4). However, we understand the limitation of such approach and that having a 2D distribution of velocities (not available for the datasets) would most likely enhance migration efforts. Nevertheless, EM wave velocities interpreted at two or more locations within each sedimentary unit retrieved consistent velocities as shown in the results section. For that reason, and although we acknowledge the presence of some diffraction hyperbolas that did not collapse after migration (Figure 4) (which may be indicative of velocity being used that is too low), we are confident that our estimated velocity is representative of the materials found at the study site.

\section{Electrical resistivity imaging (ERI)}

$E R I$ is an imaging technique that measures the spatial variation of the subsoil bulk resistivity by means of multi-electrode systems (Griffiths and Barker, 1993). The most common configuration consists in actively transmitting an electrical current pulse through electrodes, galvanic-coupled to the ground, while the potential induced to the ground is recorded at specific locations in other electrodes according to a specific array. Among
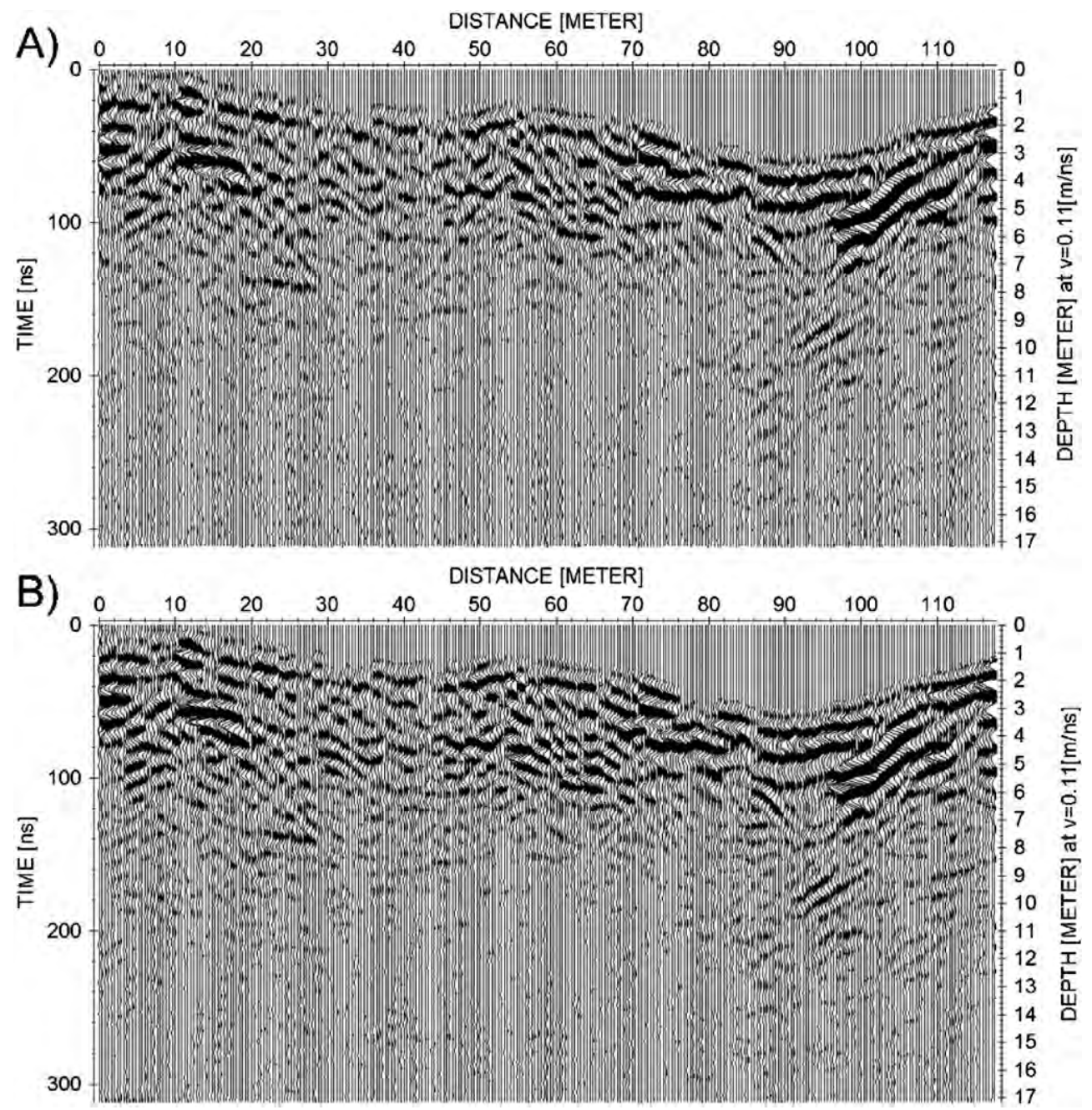

Figure 4. Example of unmigrated (A) and migrated profile (B) after applying a Kirchhoff migration with a summation width of 30 and a velocity of $0.11 \mathrm{~m} \mathrm{~ns}^{-1}$. Profile acquired with an IDS-RIS system and an unshielded $60 \mathrm{MHz}$ frequency antenna. 
all parameters governing bulk resistivity, the pore-fluid content and hydrochemistry are probably the most influential (Archie, 1942; Urish, 1981; Zarroca et al., 2011, 2014a), which can determine variations in the resistivity value of several orders of magnitude. Since deformation structures (e.g. collapse faults) and deposits associated with sinkholes typically exhibit significant changes in moisture content and textural characteristics, ERI can be postulated as a useful method for sinkhole exploration. Furthermore, and despite having less resolution when compared to GPR, ERI has lower physical limitations in terms of signal transmission, thereby allowing greater investigation depths. Therefore, ERI and GPR can provide complementary results for sinkhole investigation (Kruse et al., 2006; Carbonel et al., 2014, 2015; De Giorgi and Leucci, 2014).

The ERI data were collected using a Lund Imaging system (ABEM SE, Sundbyberg) composed by a tetra-channel SAS4000 meter, an ES1064c switching box, and 64 electrodes. An inter-electrode spacing of $3 \mathrm{~m}$ was selected considering the depth and geometry of the targeted features. In order to enhance the galvanic contact between the soil and electrodes, a salt-bentonite-water mix was spread around the contact area, and all contact resistance was checked to be below 1.5 $k \Omega$ prior to data gathering. Three to six reverse measuring cycles with long current injection periods (1.2 seconds) were used to deal with self-potential cancellation (noise). The apparent resistivity was recorded using both the dipole-dipole (DDP) and the combined Wenner-Schlumberger (WS) arrays, which have very different sensitivity functions and horizontal data coverage (Pazdirek and Blaha, 1996; Dahlin and Zhou, 2004; Loke, 2015). The use of both configurations was aimed at assessing the capability of each array type to image targets. Additionally, a hybrid resistivity image was also constructed by merging both the WS and DDP apparent resistivity measurements. This was aimed at increasing data saturation and diminishing inversion artefacts caused by the sensitivity function for each array. The hybrid WS+DDP image preserves the valuable lateral resolution provided by the DDP array, while reasonable resolution is also achieved at higher depths due to the favourable depth-to-noise ratio of the WS array. It should be noted that the investigation depth of the DDP survey had to be limited due to its poor signal-to-noise ratio. The highresistivity of the terrace gravels caused severe weakening of the induced voltage in the deepest recording levels. Therefore, the deeper zone of the hybrid image was constructed solely on the basis of the WS records.

The apparent resistivity records gathered at different pseudodepths (pseudosections) were processed by the Earthlmager2D inversion software (Advanced Geosciences, Inc., Austin, TX). This software solves the non-linear inversion problem by the least-square smoothness-damping constrained method (Occam's inversion) (Constable et al., 1987; LaBrecque et al.,
1996; Loke, 2011). Regarding the quality assessment, the resistivity images were constructed with significant data saturation, which enables imposing a rigorous data filtering without compromising the resolution (Table I). Data suspected to be unreliable (i.e. negative resistivity values, records with a variation coefficient during the measuring cycle over $2.5 \%$; and poorly-fit data according to a statistical misfit after a preliminary inversion) were removed after the inversion process. Figure $5 \mathrm{~A}$ shows an example of the wide data coverage across all the filtered pseudosections, with the exception of the deeper levels at the southeast edge. According to the data misfit (Figure 5B), only a few data points at the bottom levels (below 18-20 m) exhibit noticeable model residuals [root mean square (RMS) $>20 \%$. This is expected due to the well-known decrease in sensitivity and the current signal loss of ERI at depth. Although blocky inversion likely might solve more accurately resistivity boundaries (Loke et al., 2003), the smoothed inversion by finite elements method was selected due to its stability and consistency. The complete Gauss-Newton method, which recalculates the sensitivity matrix at each iteration as opposed to the quasi-Newton method, was used to preserve the maximum resolution. The starting model for the inversion was set to a resistivity equal to the measured apparent resistivity values (i.e. pseudosection), after filtering, to exclude potential noisy data. The maximum and minimum modelled resistivity values were restricted $10^{5}$ and $10^{-1} \Omega \mathrm{m}$, to enhance the model consistency. The profile of the ground surface was also recorded to enable topographic correction of the resistivity model. RMS or L2-norm standardized errors over the final model (resistivity image) provided information on its residuals (i.e. statistical misfit between measured and calculated pseudosections). Furthermore, the relative model sensitivity (Figure 5C) also enables to account for poorly constrained areas and to establish a more reliable DOI. The relative sensitivity (SR) of each area was classified as follows: low $\left(\mathrm{SR}<10^{-3}\right)$, medium $\left(10^{-3}<\mathrm{SR}<1\right)$ and high $(\mathrm{SR}>1)$. The DOl-index also enables assessing the depth below which the resistivity model is poorly constrained, and the imaged features are no longer controlled by the data (Oldenburg and Li, 1999). The DOIindex was computed considering constant 70 and $7000 \Omega \mathrm{m}$ starting models (respectively 0.1 and 10 times the average of the apparent resistivity records). A DOI cutoff value of 0.1 to 0.2 has been widely reported in the literature (e.g. Oldenburg and Li, 1999), although many authors consider that would be more suitable to select the limit according to the maximum gradient line (e.g. Oldenborger et al., 2007; Caterina et al., 2013). In our case, both criterions would advise to interpret with extremely caution features imaged below 10-15 m. Nevertheless we consider that the DOI-computing may be strongly influenced by the local subsoil configuration, due to the high resistivity range of the uppermost electro-unit compared with

Table I. Features of electrical resistivity imaging profiles collected in April 2013, and quality assessment of the raw data

\begin{tabular}{|c|c|c|c|c|c|c|c|}
\hline Profile & Spacing $^{\mathrm{a}}(\mathrm{m})$ & Collected data-points $^{\mathrm{b}}$ & Rejected data-points ${ }^{\mathrm{c}}$ & Cutoff $^{d}$ & Inverted data-points ${ }^{\mathrm{e}}$ & $\operatorname{RMS}^{\mathrm{f}}(\%)$ & L2-norm ${ }^{\mathrm{g}}(\%)$ \\
\hline WS & & 817 & $25 \%$ & $22.5 \%$ & 616 & 7.38 & 6.04 \\
\hline DDP & & 826 & $9 \%$ & $10 \%$ & 754 & 3.76 & 1.57 \\
\hline WS+DDP & 3 & 1643 & $16 \%$ & $22.5 \%$ & 1,378 & 7.72 & 6.62 \\
\hline
\end{tabular}

\footnotetext{
anter-electrode spacing.

${ }^{b}$ Excluded negative resistivity values and records exceeding maximum repeat error of 3\%.

${ }^{\mathrm{c}}$ Data points with root-mean-square (RMS) exceeding model residual cutoff threshold.

${ }^{\mathrm{d}}$ Threshold for putative erroneous data-points based on the model residuals of a preliminary inversion.

e Final data-points used for inversion.

${ }^{f}$ Root-mean-square (RMS) error between measured and calculated pseudosections at the end of the inversion process.

${ }^{\mathrm{g}} \mathrm{Sum}$ of the squared weighted data errors.
} 

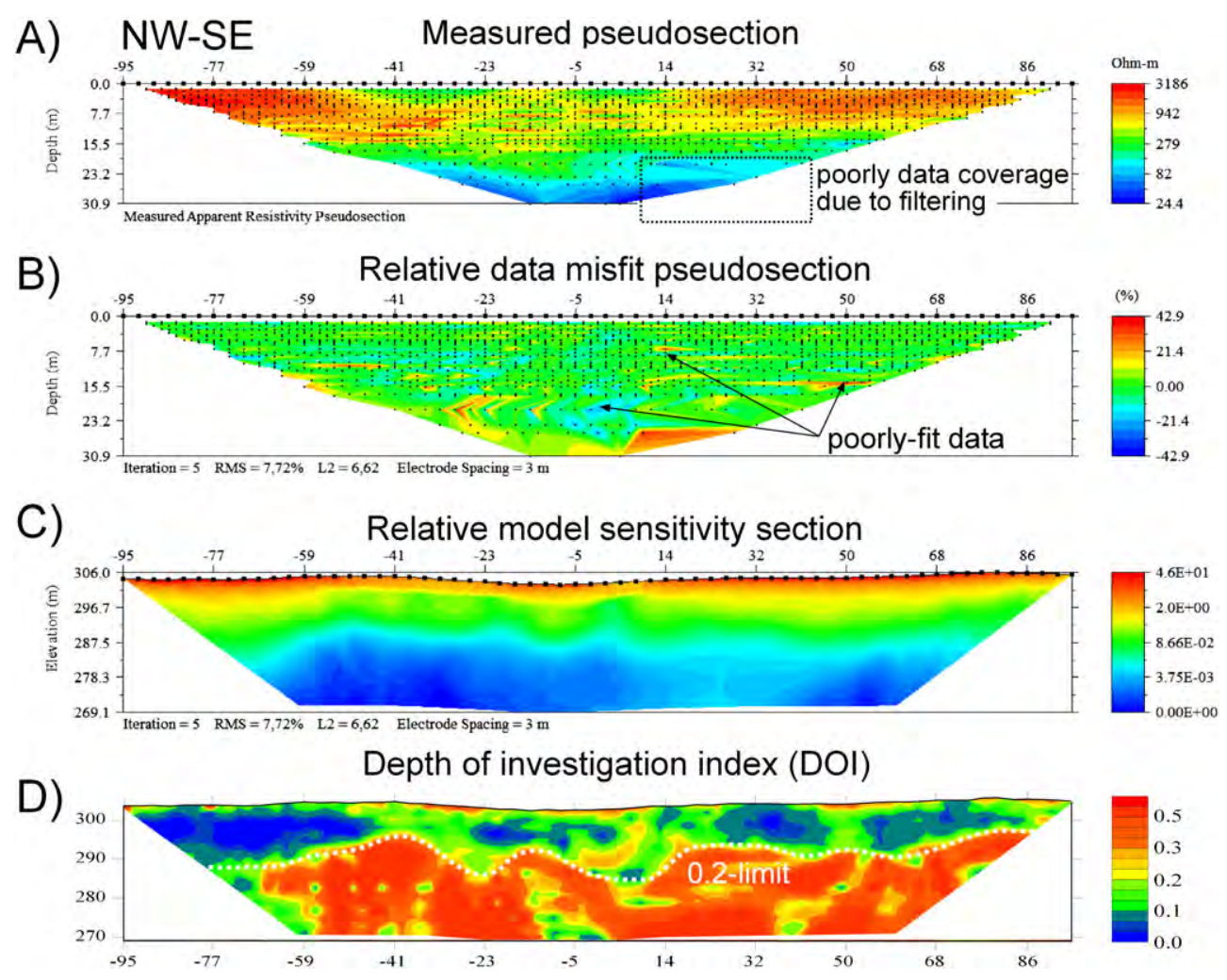

Figure 5. Quality assessment of the hybrid resistivity image (WS+DDP). (A) Measured pseudosection after filtering noisy data. (B) Data misfit pseudosection depicting model residuals, defined as relative data error between the calculated and the measured apparent resistivity records. (C) Relative sensitivity plot for the model based on the inverted resistivity image, iteration 5 computed by Earthlmager 2D software. (D) Depth of investigation (DOI) index computed from inversions over starting models of homogeneous resistivity of 70 and $7000 \Omega \mathrm{m}$. [Colour figure can be viewed at wileyonlinelibrary.com]

the underlying one. Accordingly, we consider that sensitivity approach should be more suited than DOI-index to quantitative appraisal of the resistivity features (Caterina et al., 2013), at least in the studied site.

\section{Results}

\section{Description and analysis of the logged exposure}

The artificial exposure, which corresponds to the edge of an excavation in the terrace $\mathrm{T}_{10}$, is a straight and vertical cutting with a N130E orientation subperpendicular to the north-northeast-southwest (NNE-SW) trend of the valley (Figures 1 and 2). This southwest (SW)-facing wall is $370 \mathrm{~m}$ long and reaches 6-7 $\mathrm{m}$ in height. A detailed log of a $120 \mathrm{~m}$ long section that includes a sagging and collapse subsidence structure was constructed (Figure 3). This paleosinkhole affects two stacked channel complexes with markedly different sedimentological features influenced by the synsedimentary subsidence phenomenon. The fluvial deposits show an open and asymmetric sagging structure with ill-defined edges situated around the vertical reference lines 10 and 112 . The fold is offset on its southeast (SE) limb by a synthetic down-to-the-northwest (NW) normal fault. Three main sedimentary packages have been differentiated bounded by major erosional surfaces (PI, PII, and PIII). The lower package (PI), with an exposed thickness of $6.4 \mathrm{~m}$, occurs on both sides of the collapse fault and can be divided into three units. The lowest exposed unit (Pla) mainly consists of tabular beds of massive and crudely bedded, polymictic, unsorted to moderately sorted, rounded cobblepebble gravel. The gravel sheets are up to $2 \mathrm{~m}$ thick, include thin beds of massive sand, and are locally interrupted by well-defined ribbon-shaped secondary channels filled with massive gravel and subordinate cross-bedded sand. This unit shows gentle inward dips of around $5^{\circ}$ on both limbs of the asymmetric sagging structure, approximately $100 \mathrm{~m}$ wide. Beyond the vertical reference lines 10 and 112, including the portions of the wall not covered by the log, the unit shows a clear horizontal attitude. In the footwall of the normal fault, the intermediate unit of package I $(\mathrm{Plb})$ is represented by the edge of a broad gravel channel more than $3.5 \mathrm{~m}$ thick carved in the underlying unit. The channel fill consists of massive and crudely stratified pebble-cobble gravel with interbedded gravelly sand and rip-up clasts of massive mud up to $1.4 \mathrm{~m}$ long. The apparent $10^{\circ}-20^{\circ}$ dip of the strata and the erosional base of the channel is partially related to tilting associated with the development of the sagging structure. In the downthrown block of the normal fault the intermediate unit (PIb) consists of a sheet-like bed of massive coarse gravel that thickens towards the SE. It shows large rip-up clasts and local basal scours. This unit has an apparent SE dip of around $5^{\circ}$ in the vicinity of the fault and its top shows a minimum elevation difference of $3 \mathrm{~m}$. The upper unit of package I (PIc) is restricted to the downthrown block of the collapse fault. In the NW sector of the trench the unit is composed of $2.7 \mathrm{~m}$ of well-stratified and well-sorted pebble-granule gravel. In the sector next to the fault this upper unit is composed by overbank fines with a minimum thickness of $2.5 \mathrm{~m}$ (i.e. the upper contact is erosional) and shows an overall fining-upward sequence. The lower part consists of thin beds of bioturbated silty sand. The upper part consists of massive greyish brown marls overprinted by bioturbation (rizhoconcretions), secondary carbonate and oxidation horizons. Some beds within this unit show offlap relationships, suggesting periods of high subsidence/aggradation ratio. Although the relationship between the different facies of the upper unit have been obscured by the erosional channel of package PII, it seems probable that it corresponds to a lateral 
facies change controlled by the subsidence phenomenon and the relative position of the channel.

The two lower units of package PI, corresponding to architectural elements GB (gravel bars) and $\mathrm{CH}$ (channel), and dominated by $\mathrm{Gm}$ lithofacies (massive gravel), can be interpreted as a broad and shallow braided gravel channel with longitudinal bars and multiple inter-bar and bar-top secondary channels (Miall, 1978, 1985, 1996). The spatial correlation between the SE edge of the channel of unit Plb and that of the sagging structure, suggests that the location of the channel was controlled by the development of a large sinkhole. In the downthrown block, the upper unit of package I, composed of fine-grained palustrine facies (element OF; overbank fines) and stratified pebble-granule gravel, can be collectively ascribed to deposition in a large subsidence depression (sagging sinkhole) within the floodplain. Probably, the shallower marginal sectors close to the channel received well-sorted fine gravels during flood events. These sediments may be equivalent to the 'gravel lobes' described by Luzón et al. (2008) in synsedimentary paleosinkholes found in terrace deposits of the Ebro River. This architectural element is interpreted as gravelly crevasse splays derived from a nearby active braided channel that grade to and interfinger with the palustrine facies accumulated in paleosinkholes (figure 9 of Luzón et al., 2008). The fining-upward sequence in the overbank fines, changing from sand to marl facies, together with offlap relationships, suggest a progressive deepening of the paleosinkhole indicative of more rapid subsidence than aggradation. Subsidence in this 'starved' depression led to the development of a palustrine area with an oscillating water table close to the surface (Kraus and Middleton, 1987; Kraus, 1992).

The intermediate package (PII), with an exposed thickness of $5.2 \mathrm{~m}$, is restricted to the downthrown block of the collapse fault. It corresponds to a channel carved into the sagged package PI. Two main units can be differentiated in this sanddominated channel. The lower unit (PIla) includes a basal bed of massive pebble-cobble gravel that drapes the erosional base of the channel (channel lag), and an asymmetric sandy channel fill spatially associated with the synformal structure. The NW margin of the channel shows a sequence of offlapped concave-up sand bars recording lateral accretion (architectural element LA with epsilon cross-bedding). The core of the channel is filled by silty sand beds with normal grading and overall trough-cross stratification. These sandy beds mainly show crude internal banding concordant with the dipping upper and lower limits. The exposure conditions of the upper unit of this package (PIIb) were less favourable and their improvement by cleaning was hindered by safety issues. The unit is mainly composed of massive silty sand with secondary ribbon-shaped channels filled with cross-bedded sand and fine gravels. This unit overlaps the underlying unit recording the expansion of the depositional zone in the channel. Between the vertical reference lines 52 and 76 the sand is overlain by the remnant of an apparently shallow channel filled with massive gravel.

The intermediate package (PII) records the development of a channel upon a swampy depression in the floodplain, suggesting an avulsion process conditioned by a large starved sagging sinkhole. The presence of LA-architectural element (Miall, 1985) bodies and the unusual sand facies of the channel fill are indicative of local gradient conditions favourable for the development of a sinuous channel with low competence flows and suspended load deposition. Probably the lateral channel migration recorded by the LA bars was influenced by the relative position of the sinkhole sector with higher subsidence. The terraces of the Gállego River in the area are dominated by coarse gravel channel facies (Benito et al., 1998, 2010).
The upper package (PIII) corresponds to a man-made deposit composed of chaotic pebble gravel with reddish-brown silty sand matrix. This fill is restricted to the bottom of a topographic depression associated with the normal fault and its adjacent downdropped block. Initially, this bowl was thought to be a modern sinkhole related to displacement on the underlying fault and sagging structure. However, evidence derived from detailed mapping of the outcrop suggests that it is not related to active subsidence since: (1) there is lack of concordance between the topography and the structure of the underlying alluvium; (2) the normal fault is truncated by the anthropogenic deposits, and consequently postdates its most recent displacement episode. The most likely explanation is that the depression, located next to the abandoned village of Puilatos, corresponds to an old excavation used to extract fine-grained aggregate. The man-made fill reaches a maximum thickness of $1.3 \mathrm{~m}$ below the lowest point of the depression, where a pipe subperpendicular to the wall was installed during the construction of Puilatos village (sewage system).

The sagging structure, although expressed as an open synform approximately $100 \mathrm{~m}$ wide, should correspond to a basin structure with centripetal dips. Assuming a chevron geometry for the asymmetric fold and a constant dip of $3^{\circ}$ on the NW limb, we can roughly estimate a vertical displacement of around $4 \mathrm{~m}$ related to passive bending. The studied section most probably does not coincide with the deeper part of the structure, where the actual dips and the vertical displacement can be significantly higher. The geometrical relationships and the sedimentological features of the deformed sediments indicate that sagging was active during deposition of packages I and II, controlling channel location, a change in the channel pattern and the development of a swampy area. The normal fault is probably the youngest deformation observed in the exposure; it seems to be superimposed on the sagging structure and is postdated (truncated) by the anthropogenic fill. This fault dips $80 \mathrm{NW}$ and shows shear fabrics with reoriented clasts. It has a minimum throw of $2.4 \mathrm{~m}$, given by the vertical distance between the top of unit Plb on both sides of the fault. The actual value can be considerably higher, since the upper part of the unit has been eroded from the footwall. Commonly, normal faults related to collapse structures have a cylindrical or conical 3D geometry and consequently are displayed as graben-like structures in 2D sections. However, no antithetic counterpart has been observed in the exposure. This might be related to some kind of asymmetry in the collapse structure. Luzón et al. (2008) have documented a similar asymmetric sagging and collapse paleosinkhole resembling a half-graben in cross-section in a terrace of the Ebro River. Complex paleosinkholes comprising a sagging basin structure with a nested collapse structure superimposed in its central sector are common in the central sector of the Ebro Basin (e.g. Gutiérrez et al., 2008b; Guerrero et al., 2013).

\section{Geophysical survey}

GPR results show differences both in vertical resolution and penetration depth depending on the system and antenna frequency used. Figure 6 shows the GPR profiles obtained using the IDS unshielded $60 \mathrm{MHz}$ and shielded $160 \mathrm{MHz}$ frequency antennas with approximate vertical resolutions of 0.45 and $0.17 \mathrm{~m}$, respectively. As expected, the lower frequency antennas yield increased depth of penetration, reaching $10 \mathrm{~m}$ in places (when considering a flat topography), and when compared to maximum depths of penetration of $6 \mathrm{~m}$ for the higher frequency antennas. It is important to note that in both cases (and despite the difference in antenna frequency) signal 


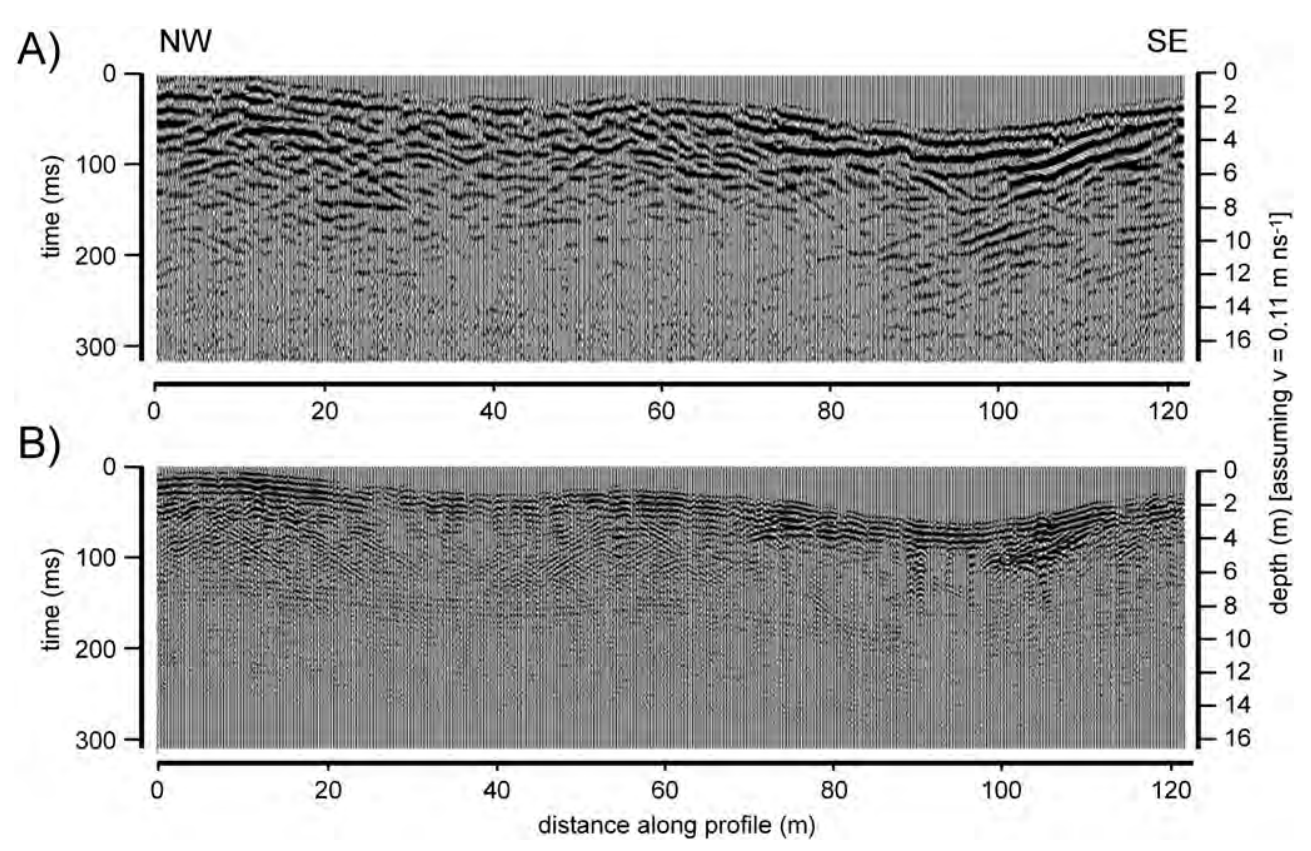

Figure 6. Ground penetrating radar (GPR) common offset profiles collected along the top of the exposed outcrop using a IDS-RIS system with: (A) an unshielded $60 \mathrm{MHz}$ frequency antenna; and (B) a shielded $160 \mathrm{MHz}$ frequency antenna. Both profiles were processed following the same filtering routine, including a topographic correction and migration using an average electromagnetic (EM) wave velocity of $0.11 \mathrm{~m} \mathrm{~ns}^{-1}$.

attenuation is patent approximately below $150 \mathrm{~ns}$, and is most likely the reason for limiting depth of penetration for both frequencies. Certain differences in the reflection record can be seen in the common offset profiles acquired with the RIS system. A set of marked laterally continuous and planar shallow reflections (i.e. first $2-3 \mathrm{~m}$ depth from the surface) can be differentiated at $x$-coordinate intervals $0-25 \mathrm{~m}$ and $70-120 \mathrm{~m}$ along the profiles. Such reflection pattern contrasts with a set of discontinuous and wavy reflections between 25-70 $\mathrm{m}$ for the same approximate depths. Although Figure $6 \mathrm{~A}$ shows depths of penetration down to 8-10 $\mathrm{m}$ depth, overall reflection patterns are difficult to interpret below 5-6 m depth. Figure 7 shows results for the HDR shielded $160 \mathrm{MHz}$ frequency antennas. In this case vertical resolution is enhanced with values of about $0.15 \mathrm{~m}$ and depths of penetration of 7 to $8 \mathrm{~m}$. The reflection record shows shallow patterns similar to those depicted in Figures $6 \mathrm{~A}$ and $6 \mathrm{~B}$, however given the unique capabilities of this HDR antenna, vertical resolution is improved and thus allow for a more confident interpretation of the reflection record, as shown in Figure 7B. It should be mentioned, however, that our interpretation in Figure $7 \mathrm{~B}$ shows areas of less confidence (as indicated by dashed lines) that rely in comparisons with boundaries as defined by the profiles shown in Figure 6.

From younger to older materials, package PIII is characterized by a sequence of laterally continuous reflectors extending between 80 to $100 \mathrm{~m}$ along the profile and maximum thickness below $2 \mathrm{~m}$ (Figure 6B). Based on the location of GPR reflectors interpreted as interfaces between units and packages, the average EM wave velocity for this package is $0.090 \mathrm{~m} \mathrm{~ns}^{-1}$. Package PII is located between $x$-coordinate $10-80 \mathrm{~m}$ along the profile and two different units can be inferred: Pllb on top with an average thickness of $2 \mathrm{~m}$, underlain by Plla with a thickness ranging between 1 and $4 \mathrm{~m}$. Pllb is characterized by moderately continuous and subplanar reflectors somewhat attenuated when compared to PIII. Plla, dominated by large trough cross-

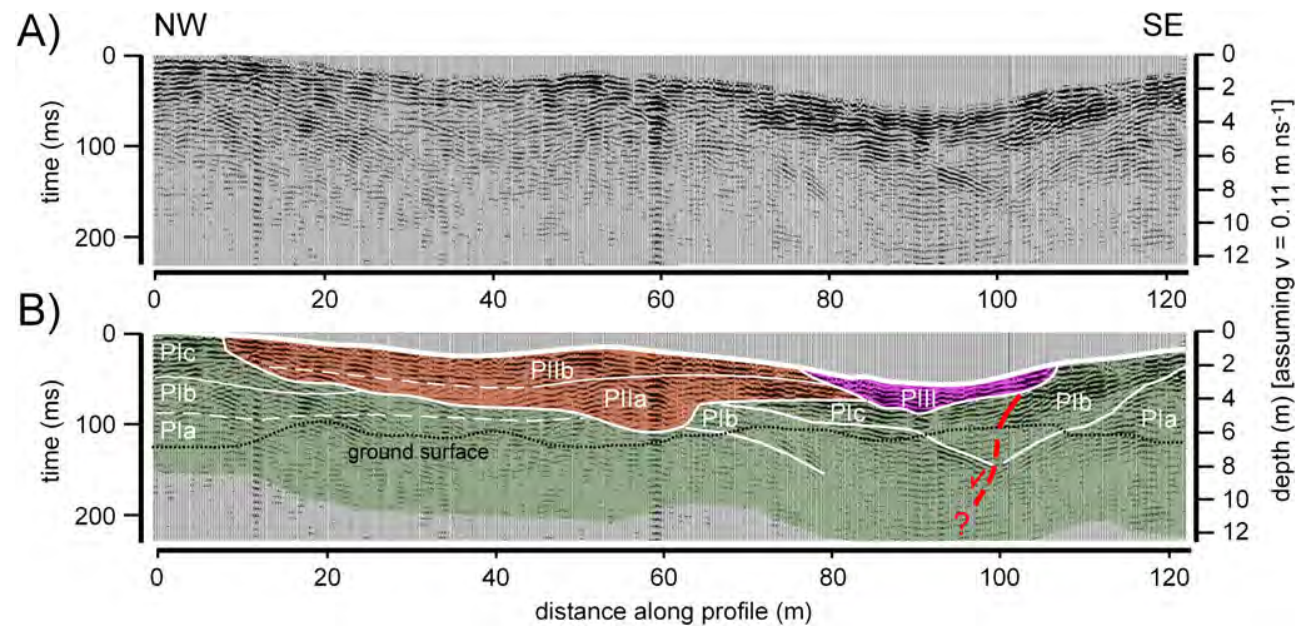

Figure 7. (A) Ground penetrating radar (GPR) common offset profile collected along the top of the exposed outcrop using a MAL $\AA$ GroundExplorer (GX) system with a shielded high dynamic range (HDR) $160 \mathrm{MHz}$ frequency antenna. The processing routine mimics that used for the other GPR profiles assuming an average electromagnetic (EM) wave velocity of $0.11 \mathrm{~m} \mathrm{~ns}^{-1}$. (B) Interpretation of the morpho-stratigraphic architecture based on the GPR results earlier. [Colour figure can be viewed at wileyonlinelibrary.com] 
bedding, shows even more attenuation, perhaps due to the higher depth, and is characterized by a set of mainly dipping reflectors. Estimated EM wave velocities average 0.105 and $0.011 \mathrm{~m} \mathrm{~ns}^{-1}$ for Plla and PIlb, respectively. Package PI is distributed along the whole profile and three units can be inferred according to the outcrop and reflection patterns: (1) Plc, located between $0-20 \mathrm{~m}$ and $65-100 \mathrm{~m}$, is characterized by subparallel and planar reflections with an average EM wave velocity of $0.098 \mathrm{~m} \mathrm{~ns}^{-1}$; (2) Plb, located between 0-50 m, 60$100 \mathrm{~m}$ and $100-120 \mathrm{~m}$, displays reflectors dipping towards SE in the first and second portions, and NW in the last sector, corresponding to the sagging structure described earlier, and an average EM wave velocity of $0.096 \mathrm{~m} \mathrm{~ns}^{-1}$; and (3) Pla, located between $0-80 \mathrm{~m}$ and $100-120 \mathrm{~m}$, is characterized by overall subparallel wavy reflectors with an average velocity of $0.10 \mathrm{~m} \mathrm{~ns}^{-1}$.

The normal fault described from the exposure is also interpreted in Figure 7B as superimposed to the sagging structure and truncated by the anthropogenic fill. The fault can be traced below the outcrop. A set of three to four conspicuous SE-dipping reflections located between 95 and $100 \mathrm{~m}$ along the profile and $7-8 \mathrm{~m}$ depth show a sharp lateral change into NW dipping reflections located between 100-110 m and 6-9 $\mathrm{m}$ depth. This cross-cutting relationship is interpreted as the continuation of the fault below the ground surface and the base of the cutting (Figure 7B). Based on this interpretation a throw of approximately $4 \mathrm{~m}$ can be estimated for the fault $(2.1 \mathrm{~m}$ if only considering the exposed portion as shown in Figure 7B).

The resistivity images show two main units with contrasting electrical properties (Figure 8). A high-resistivity unit (1000-5000 $\Omega \mathrm{m})$, which corresponds to the exposed stacked channels (packages PI and PII), is 10-15 m thick and overlays an unexposed lower-resistivity unit $\mathrm{P0}(<50 \Omega \mathrm{m})$ that extends to the bottom of the image. Unit P0 most probably corresponds to a massive clay-rich karstic residue related to the dissolution of the halite-bearing evaporitic bedrock. It could be also interpreted as evaporitic bedrock consisting of gypsum/anhydrite and marls characterized by low resistivity values (< $50 \Omega \mathrm{m}$; Guinea et al., 2010). However, several lines of evidence support the karstic residue interpretation: (1) in this region, the Quaternary alluvium is rarely in direct contact with the evaporitic bedrock, whose upper part has been commonly transformed into a thick karstic residue; (2) the log of the borehole drilled in the large sinkhole situated south the investigation site reveals a karstic residue $c .50 \mathrm{~m}$ thick between the alluvial cover and the bedrock (Figure 2B); (3) unit P0 is imaged in the sections as a homogenous medium, which is more consistent with a massive residual material than with a layered substratum (low-resistivity marls and high-resistivity halite- and gypsum-bearing beds). The non-weathered bedrock may be situated below the penetration depth of the survey or it may have not been captured because low-resistivity layers favour current conduction and limits the information on the subjacent material (Loke, 2015). The contact between units PO and PI-PII is quite irregular, especially in the DDP section. Overall, the hybrid DDP+WS image displays a resistivity pattern similar to those in the WS and DDP sections (Figure 8). The irregular contact between the alluvium (PI-PII) and the underlying karstic residue $(\mathrm{PO})$ is inherited from DDP, with higher horizontal resolution. Two medium-resistivity units (100-500 $\Omega \mathrm{m}$ ) of limited thickness partially cover the PI-PII unit (between $x$-coordinate -48 to $+14 \mathrm{~m}$ ). The NW portion correlates with the sand-dominated unit PIlb mapped in the exposure, while the SE portion seems to image both the man-made fill (package PIII) and the palustrine sediments deposited within the sinkhole (unit PIc). It should be noted that, despite the fact that reasonable correlations between both resistivity and stratigraphic units can be established, locally, there is considerable ambiguity since different facies may show very similar resistivity signatures.

\section{Discussion}

The detailed log of the exposure constitutes the basis for characterizing the paleosinkhole and reconstructing its

\section{A) NW-SE}

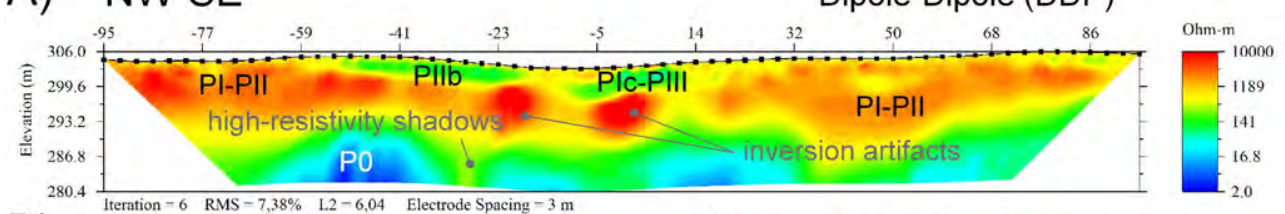

B)

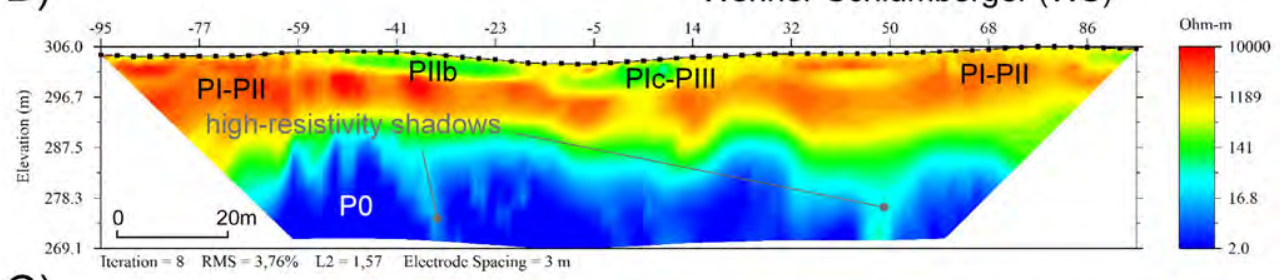

C)
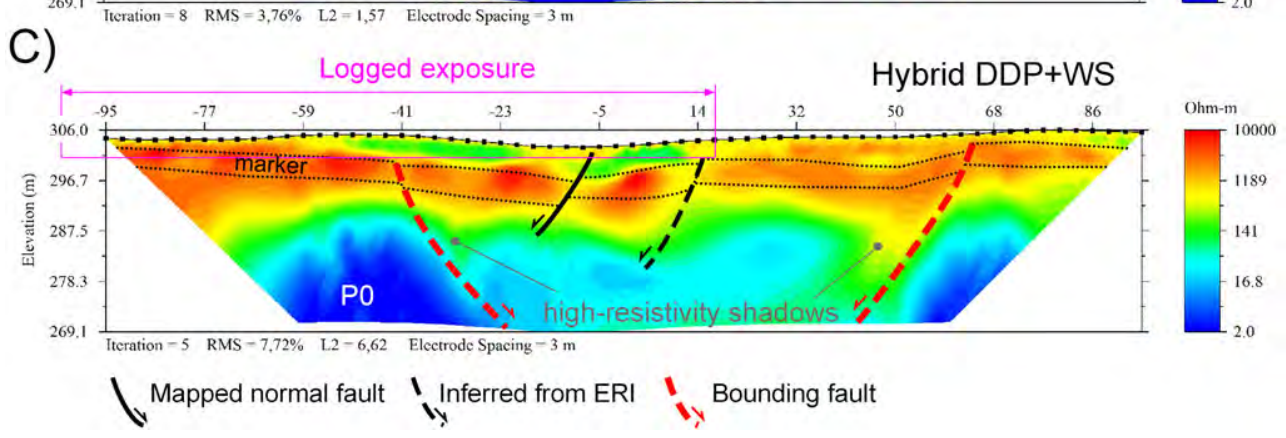

Figure 8. Inverted resistivity image collected in April 2013 by (A) dipole-dipole (DDP) and (B) Wenner-Sclumberger (WS) arrays. (C) Hybrid resistivity image performed by inverting a joined DDP and WS apparent resistivity data set. [Colour figure can be viewed at wileyonlinelibrary.com] 
deformational and depositional history. The observed stratigraphic and structural relationships, together with the associated sedimentological features (architectural elements and lithofacies), allows inferring the following evolution, as illustrated in the retrodeformation sequence shown in Figure 9. Most likely the sagging subsidence was active before deposition of the gravel channel corresponding to unit Plb (Figure 9, stages 1 and 2). The SE edge of this channel roughly coincides with the margin of the sagging structure, suggesting that the location of the channel was controlled by differential settlement. The sedimentological characteristics of this unit, dominated by $\mathrm{GB}$ and $\mathrm{CH}$ elements and facies $\mathrm{Gm}$, indicate a broad braided gravel channel with multiple longitudinal gravel bars that fits with the architectural style of Model 3 proposed by Miall (1985). The change from gravel channel facies into overbank fines of unit Plc, including marly backswamp facies (Kraus and Middleton, 1987; Kraus, 1992), can be interpreted as the shift of the channel and the development of a progressively deeper palustrine area in the floodplain associated with a large active sinkhole (Figure 9, stage 3). The sandy channel with lateral accretion sand bars corresponding to package II, and excavated in the central sector of the sagging structure, records the development installation of a new channel in the subsidence area and a marked change in the depositional style (Figure 9, stage 4). This package fits with the architectural style of Model
6 proposed by Miall (1985) for sandy, mixed-load meandering rivers. Probably, the normal fault is a post-sedimentary structure formed sometime after deposition of the described alluvial sediments, which have been partially removed by human activity in recent times (Figure 9, stages 5 and 6). This evolutionary sequence reveals that the development of large sagging sinkholes may have a strong local influence on the dynamics of the fluvial system and its morphological and depositional patterns:

1 Long-sustained control on the location of channels, which tend to be confined and stacked in the subsidence areas. Subsidence in the floodplain may lead to a relative superelevation of the channel, controlling avulsion and migration processes (Leeder and Gawthorpe, 1987; Alexander and Leeder, 1990). In the Jalón and Huerva valleys, northeast Spain, the channels within terrace deposits thickened and deformed by dissolution-induced synsedimentary subsidence tend to be associated with the hinge zone of sagging structures (Gutiérrez, 1996; Guerrero et al., 2008). In the Jalón and Alfambra valleys, Iberian Chain, northeast Spain, Gutiérrez $(1996,1998)$ recognized conspicuous deflections and sinuosity changes in the present-day river channel controlled by large subsidence depressions related to evaporite dissolution.

\section{6}

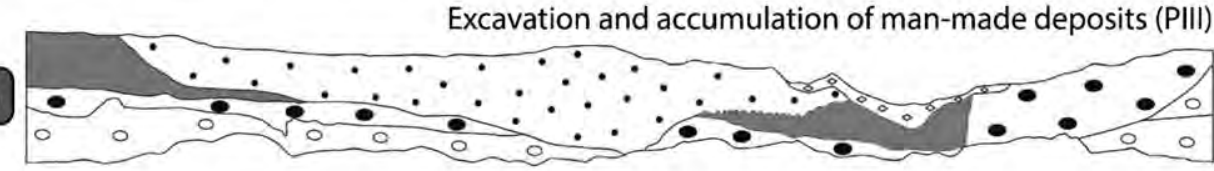

Faulting of packages $\mathrm{PI}$ and PII

5

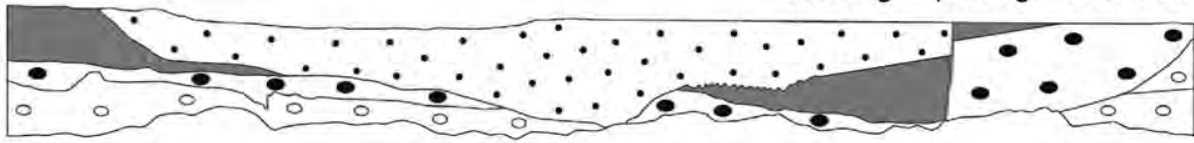

Sandy channel on subsiding swampy depression (PII)

4

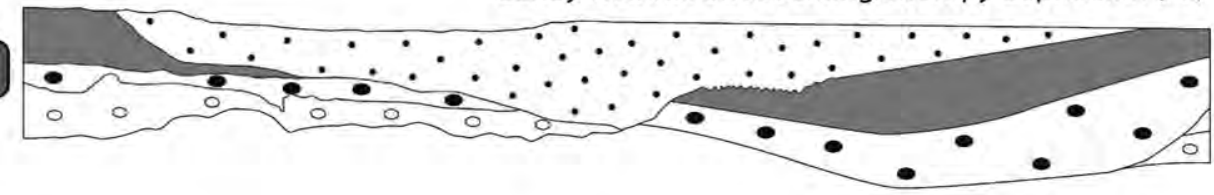

3

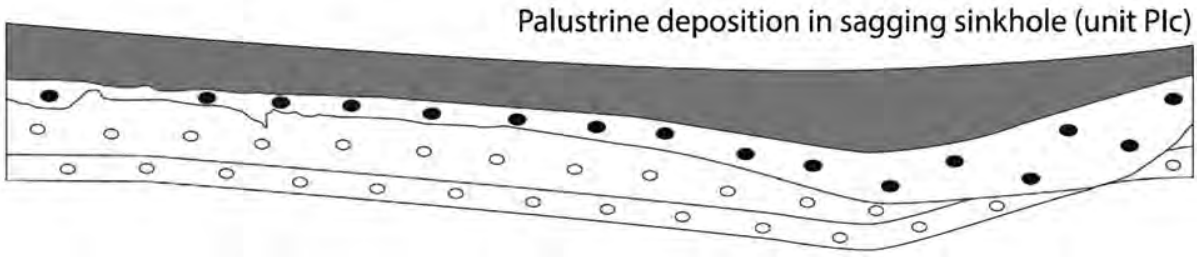

Deposition of gravel channel controlled by sagging sinkhole (unit PIb)

2

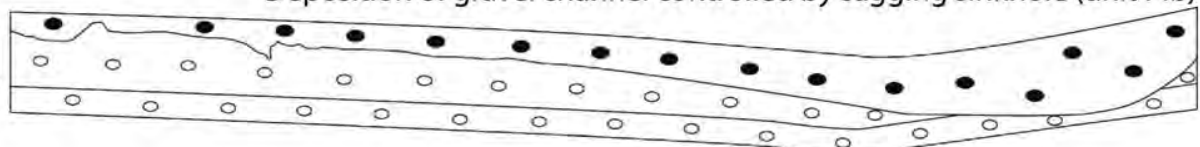

Deposition of channel gravel (unit Pla)

1

\begin{tabular}{|llllllllllllllllll|}
\hline 0 & 0 & 0 & 0 & 0 & 0 & 0 & 0 & 0 & 0 & 0 & 0 & 0 & 0 & 0 \\
\hline 0 & 0 & 0 & 0 & 0 & 0 & 0 & 0 & 0 & 0 & 0 & 0 & 0 & 0 & 0 \\
\hline
\end{tabular}

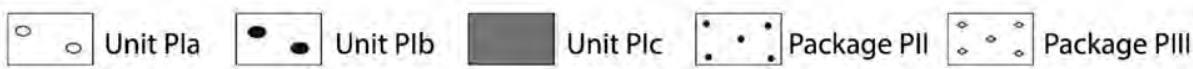

Figure 9. Simplified retrodeformation analysis $(\times 2$ vertical exaggeration) illustrating the interaction between dissolution-induced subsidence and fluvial dynamics and deposition. 
2 Development of swampy and ponded areas in the floodplain where subsidence is not counterbalanced by aggradation. The formation of modern and past palustrine areas and small lakes associated with sinkholes in fluvial systems has been documented in numerous geomorphological and sedimentological studies conducted in the evaporitic central sector of the Ebro basin (Gutiérrez and Arauzo, 1997; Benito et al., 1998; Valero-Garcés et al., 2004; Guerrero et al., 2008, 2013; Luzón et al., 2008; Galve et al., 2009; Gutiérrez et al., 2011). A present-day analogue for the palustrine deposition recorded by unit Plc can be observed $500 \mathrm{~m}$ south of the studied outcrop. Here, there is an active sinkhole c. 400 $\mathrm{m}$ across that hosts a lake with palustrine vegetation (Figures 1 and 2). This lake has been developed over a few decades, since it is not recognizable in aerial photographs from 1957. Active subsidence, at rates of the order of centimetres per year, causes continuous damage in the $\mathrm{N}-330$ motorway and the A-23 Zaragoza-Huesca highway, and has affected the operation of an artificial channel due to gradient reversal.

3 Spatial and temporal changes in the channel pattern (e.g. sinuosity, width/depth ratio, sediment load) related to alterations in the valley gradient caused by subsidence (Schumm and Khan, 1972; Ouchi, 1985; Schumm, 1986; van den Berg, 1995). Based on a morpho-stratigraphic analysis of the thickened terraces of the Gállego River along its lower evaporitic reach Benito et al. (1998), inferred a general change from low sinuosity gravelly braided channels to more sinuous braided channels with higher deposition of overbank fines in the subsidence areas. In the Huerva valley, Ebro Cenozoic basin, Guerrero et al. (2008) interpreted a similar channel pattern change in the subsidence areas, where the reduction in stream power promotes higher deposition of overbank fines. A remarkable change from braided to meandering pattern attributed to a decrease in the valley slope has been reported by Burbank and Anderson (2001) in rivers flowing across tectonically active basins in the foreland fold-belt west of the Pamir Range (Pakistan). Ouchi (1985) investigated the impact of subsidence on braided and meandering rivers in an experimental flume. The main responses and adjustments observed include: (i) sinuosity increase in the upstream sector of the subsidence area, where the gradient is steepened (the channel increases its length to compensate the increase in slope); (ii) rapid aggradation in the central sector of the subsidence area; (iii) increase in water depth, flooding of bars, and deposition of fine-grained sediments in the downstream reach of the subsidence area, where the slope is flattened and the stream power reduced.

From a methodological point of view, exposure logging and/or trenching allow the precise location and characterization of sinkholes and subsidence structures at shallow depth. However, the spatial distribution of concealed sinkholes may be unknown, or the excavation of trenches may not be feasible. Under these circumstances, the application of near-surface geophysical techniques may be instrumental. Their use in combination with trenching may be also highly useful, as they allow substantially an increase in the depth and spatial coverage of the investigation in a non-intrusive manner (Figure 10) (e.g. Carbonel et al., 2014, 2015).

The investigation reported here shows the potential of GPR for aiding the characterization of large concealed sinkholes. Although signal attenuation may arise when materials are electrically conductive, the method shows good potential due to its high imaging resolution, and the ability to acquire and process spatially-dense data with an acceptable cost/benefit ratio. Rodríguez et al. (2014), based on a comparative investigation of cover sagging and cover collapse sinkholes using different systems and antennas, proposed that high-frequency antennas are more suitable for detecting small sinkholes and narrow collapse faults, whereas low-frequency antennas with higher penetration depth may be more adequate for detecting large sagging sinkholes. However, it should be noted that GPR has

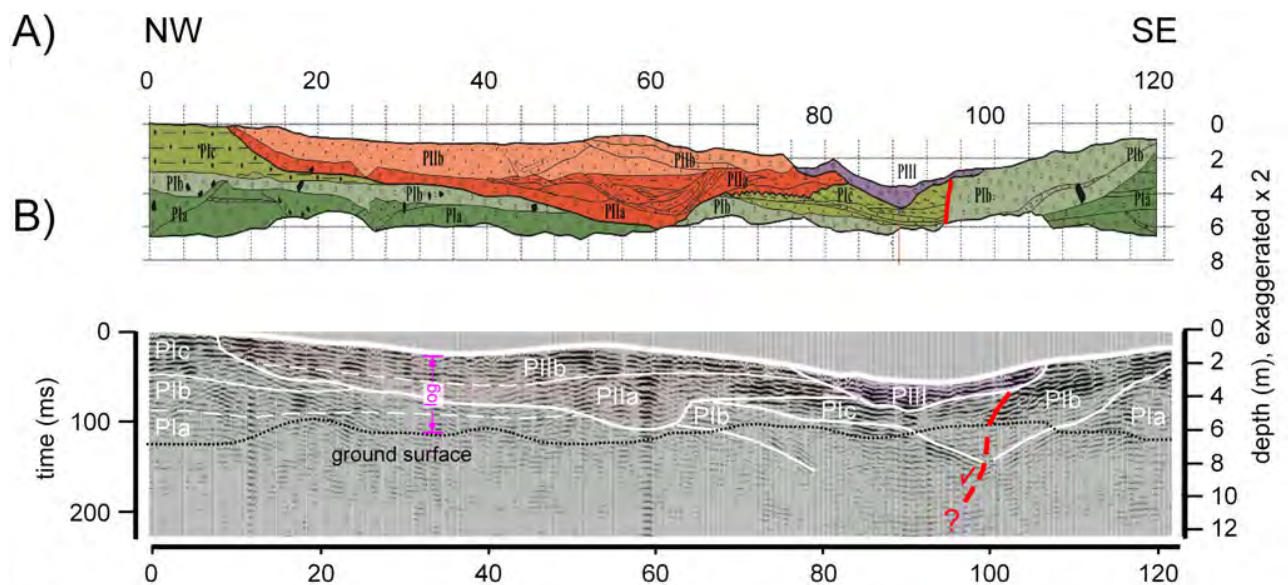

C)

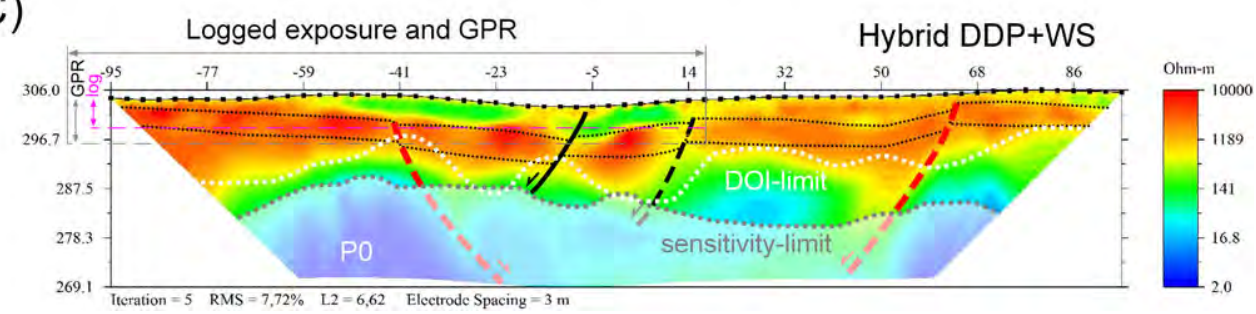

Figure 10. Comparison of the results achieved by exposure logging (A), ground penetrating radar (B) and electrical resistivity imaging $(\mathrm{C})$; symbols in Figures 3, 6 and 7. The sensitivity and depth of investigation (DOI)-index limits (C) enable better appraisal of the confidence on the imaged features. Those features imaged below such limits may be no longer constrained by the data. [Colour figure can be viewed at wileyonlinelibrary.com] 
some limitations for the detection and characterization of buried sinkholes infilled by fine-textured sediments that may significantly attenuate the radar waves and limit the DOI. In the studied example, the data gathered with the different systems (RIS, GX) and antennas (shielded $160 \mathrm{MHz}$, HDR shielded $160 \mathrm{MHz}$, unshielded $60 \mathrm{MHz}$ ) satisfactorily imaged the main geometrical features of the paleosinkhole; an asymmetric sagging structure offset by a normal collapse fault on one of the limbs (Figures 6 and 7). The sagging structure is captured as inclined reflections with opposite dips and the collapse fault as a prominent lateral interruption of the tilted reflectors. The advanced real-time sampling technology of GX system with HDR $160 \mathrm{MHz}$ antennas yielded data with higher vertical resolution and penetration depth (Figure 7) than the conventional antennas (Figure 6) and, thus, proved particularly useful for imaging sagging sinkholes related to evaporite dissolution.

The architectural elements mapped in the exposure (sedimentary packages and units) have been recognized in the HDR radargram as distinctive reflections attributed to major stratigraphic boundaries and as changes in the reflection pattern (i.e. radarfacies) consistent with the distribution of the different lithofacies. Nonetheless, it is important to note that the complex geometrical relationships depicted in the interpreted profile could not be resolved without the exposure log (Figure 7B). GPR sections are not geological cross-sections, but the recorded time-dependent response of the subsurface to the propagation of EM waves. Given the nature of the radar wave front, reflections may not come directly from beneath the survey point, and down-dip movement of reflector point signal along dipping reflectors may generate shallower apparent dips. For that reason, it is important to correct such effect using migration techniques, particularly when profiles show dipping reflectors. In our case, we used a constant velocity (i.e. $0.11 \mathrm{~m} \mathrm{~ns}^{-1}$ ) when migrating our datasets, and although our velocity analysis shows fairly consistent values for all materials (i.e. mainly between $0.95-0.11 \mathrm{~m} \mathrm{~ns}^{-1}$ ), slight changes in velocity may potentially induce erroneous placement of reflections, despite the fact that the use of both velocities resulted in the same results. Furthermore, it is also important to consider that the nature of the reflections in a GPR profile is dictated by the reflection coefficient, or contrast between the top and the bottom EM wave velocity for a particular interface. Although our GPR results, especially those obtained with the HDR $160 \mathrm{MHz}$ antenna, allow for some confident interpretation of sedimentary units and deformation structures (Figure 6 B), most reflections associated with unit boundaries are not clear, particularly as depth increases. This was expected considering the similarity between EM wave velocities for the different units, resulting in poor contrasts and thus limited reflection coefficients. This fact is supported by the marked contrast between PIII (with an average velocity of $0.09 \mathrm{~m}$ $\left.\mathrm{ns}^{-1}\right)$ and PII $\left(0.11 \mathrm{~m} \mathrm{~ns}^{-1}\right)$ along the NW boundary of the PIII unit (Figure 6B).

One of the most remarkable results from the GPR is the additional information that is provided below the outcrop. For instance, the NW-dipping collapse fault is shown as truncated by the man-made fill and can be traced below the exposure up to depths of $10 \mathrm{~m}$ (Figure 7B). Its throw can be estimated at around $4 \mathrm{~m}$, providing a more realistic figure than the minimum value measured in the exposure. Similarly, the sagging structure can be also imaged beyond the exposure, particularly in the hinge zone, as shown by the dipping Pla-Plb interface on both sides of the fault, between 60-100 m and 6-9 m depth.

Resistivity images allow for a deeper DOI, providing subsurface information well below the zone imaged by GPR (Figure 10). Furthermore, although interfaces between contrasting units are not as sharp as GPR reflectors, the differences in electrical signature of the main units are much clearer than for GPR. This is because the images capture a broad resistivity range of 2 to $10000 \Omega \mathrm{m}$ (four orders of magnitude), facilitating the identification of the main stratigraphic units; high-resistivity gravel-dominated alluvium, medium-resistivity fine-grained channel and overbank facies, and low-resistivity massive clay-rich karstic residue. Resistivity images do not provide insight into the internal geometries of the alluvium, precluding the differentiation of architectural elements. Nevertheless, resistivity images support some of the stratigraphic interpretations, such as the irregular geometry of the unconformity between the alluvium and the insoluble clayey residue, and the karstic origin of the latter, in agreement with nearby borehole data.

The use of two different arrays (WS and DDP) enables the interpretation of the resistivity distribution according to their different sensitivity functions. The DDP image shows the paleosinkhole structure with greater resolution than WS, while WS provides information on the deeper levels where the DDP shows unfavourable signal-to-noise ratio. As an alternative, the merging of WS and DDP datasets before the inversion, which results in the doubling of the number of data, allows more rigorous data filtering to be performed without compromising the model resolution. The resulting hybrid resistivity image shows additional information in some cases justifying the extra effort.

The resistivity images depict anomalies that can be interpreted as deformation structures related to the subsidence phenomena. The open and asymmetric sagging structure affecting the alluvial cover is captured by the bent high-resistivity gravel unit that serves as a marker (unit Pla). Its lateral continuity is sharply interrupted in the area of the exposed normal fault (between $x$-coordinate -10 to $-5 \mathrm{~m}$ ). This marker unit is situated within the shallow high to medium sensitivity area of the image (Figure 5C), and consequently can be considered as a reasonable interpretation. This general pattern is common in all the sections regardless of the array used. The images show other resistivity anomalies consisting of high-resistivity nodes in PI-PII (e.g. centred at $x$-coordinates -20 and $0 \mathrm{~m}$ ), which are more evident in the DDP image, and high-resistivity shadows extending through $\mathrm{P0}$, beneath some of the high-resistivity nodes (Figure 8). These anomalies might correspond to primary artefacts produced during data recording, or secondary artefacts related to the inversion process. In the first case, resistivity shadows may be generated by the particular sensitivity function of the different arrays. For example, WS show maximum positive values at the midpoint of the tetra-electrode array, which gradually decreases with depth. This sensitivity pattern might propitiate the occurrence of high-resistivity shadows below high-resistivity targets, especially for those located at the shallowest zone beneath the array midpoint (Dahlin and Zhou, 2004; Loke, 2015). However, high-resistivity shadows are also identified on DDP and hybrid images (e.g. at $x$-coordinates 35 and $+50 \mathrm{~m}$ ) (Figures $8 \mathrm{~B}$ and $8 \mathrm{C}$ ), pointing to secondary inversion artefacts that could respond to actual geological features (e.g. sharp contrast in resistivity occurring in a narrow space). The used inversion algorithm relies on the assumption that resistivity varies smoothly between adjacent model cells (Loke et al., 2003). If this assumption is not appropriate, as it may be the case in terrains with faults, the inversion routine tends to generate such kind of secondary artefacts adjacent to fractures (e.g. Fazzito et al., 2009; Suski et al., 2010; Zarroca et al., 2012, 2014b, 2015). Based on this reasoning, and because the mapped normal fault imaged by ERI is consistent with this pattern, it can be hypothesized that those resistivity anomalies correspond to buried faults that do not extend to the uppermost exposed sediments (Figure 8C). The images also 
suggest that the faults could extend deeper than $35 \mathrm{~m}$. However, the bottom of the resistivity image is a poor sensitivity area and, therefore, a deeper resistivity image would be required to confirm such fault penetration depths.

\section{Conclusions}

The presented investigation illustrates the complementarity between the implemented methods to investigate complex sinkholes, as some of their inherent limitations are synergistically overcome by other techniques (Figure 10). Trenching or exposure logging, although not always feasible, is the unique technique that allows stratigraphic and structural information to be achieved in sufficient detail to accurately reconstruct sinkhole evolution and kinematics. The analysis of the stratigraphic and structural relationships, together with the retrodeformation analysis, allows the reconstruction of the impact of the dissolution-induced subsidence phenomenon on fluvial sedimentation (Figures 3 and 9A). The analysis reveals the fluvial responses related to the development of the sinkhole (Figure 8): (1) the sagging subsidence repeatedly controlled channel location; (2) the gradual subsidence generated a ponded area in the floodplain recorded by palustrine facies located in the core of the sagging structure; and (3) it probably controlled the channel migration path and determined a local change in the channel pattern induced by local gradient variations (from gravelly braided channel to sand-dominated sinuous channel).

GPR is a good alternative in areas where trenching is not feasible or as a complementary technique, since its relatively fast acquisition rates enables gathering spatially dense data in a non-invasive and cost-effective manner. Under favourable circumstances, GPR can be used to satisfactorily identify and characterize concealed sinkholes. However, its performance can be significantly limited by the common occurrence of highly conductive clayey soils and fine-textured sinkhole fills in karst terrains. Higher vertical resolution and penetration depth are achieved with the HDR shielded antennas, despite having higher frequency than the unshielded antennas. The sagging structure is captured as conspicuous inclined reflections with opposite dips, and the normal fault as truncated reflections below the undeformed man-made fill. The results show that unravelling the complex architecture of the fluvial deposits from the GPR profiles would be ambiguous without the information provided by the exposure (or trench) log. Moreover, concave-up geometries in radargrams related to fluvial channels (e.g. unit Plla) could be misinterpreted as sinkholes, leading to hazard overestimates. Nonetheless, the higher vertical coverage of the GPR profile $(8-10 \mathrm{~m})$ compared to the exposure $(3-7 \mathrm{~m})$, allows a more realistic estimate of $4 \mathrm{~m}$ for the throw of the fault (Figure 10B).

Resistivity images, as expected, offer limited resolution. In turn, ERI has less physical constraints and offer much higher penetration depth than trenching and GPR (Figure 10C). ERI survey captures the irregular contact between the 10-15 m thick deformed alluvium and the underlying low-resistivity material $(<50 \Omega \mathrm{m})$, which probably corresponds to a massive clay-rich karstic residue, as support the borehole data. Lateral and vertical changes in resistivity within the alluvium are related to the faulted sagging structure and textural changes within the cover (gravelly versus fine-grained facies). However, these features would be difficult to interpret without the observation of the exposed subsoil. This advises that buried sagging sinkholes, lacking sharp lateral changes in resistivity compared with collapse sinkholes, may be difficult to identify without ambiguity from ERI data alone. However, comparison of images collected by different arrays, characterized by different sensitivity functions, and performing of hybrid images by merging different datasets, can enhance the ERI imaging capabilities, which largely justify the greater acquisition effort. Furthermore, the reliability of the imaged features may be appraised by the sensitivity and DOI approaches. Nevertheless, rather than assume their suitability and cutoff limits based on fixed values, which might be somewhat arbitrary, their setting according to the particularities of the site seems much more appropriate.

Acknowledgements - The authors would like to thank the two anonymous reviewers and editors for their very constructive comments and suggestions on the earlier version of this manuscript. This research was partially funded by the Spanish national project CGL2013-40867-P (Ministerio de Economía y Competitividad). Domingo Carbonel has a FPI grant of the Ministerio de Economía y Competitividad. The Division of Research at Florida Atlantic University also provided partial support for travelling and shipping of $160 \mathrm{MHz}$ HDR antennas. The authors also thank MAL $\AA$ Geosciences for their continuous technical support with GPR equipment.

\section{References}

Alexander J, Leeder MR. 1990. Geomorphology and surface tilting in an active extensional basin, SW Montana, USA. Journal of the Geological Society of London 147: 461-467.

Archie GE. 1942. The electrical resistivity log as an aid in determining some reservoir characteristics. Petroleum Transactions of AIME 146 : 54-62.

Benito G, Gutiérrez M. 1988. Karst in gypsum and its environmental impact on the Middle Ebro Basin, Spain. Environmental Geology and Water Sciences 12: 107-111.

Benito G, Pérez-González A, Gutiérrez F, Machado MJ. 1998. River response to Quaternary subsidence due to evaporite solution (Gállego River, Ebro Basin, Spain). Geomorphology 22: 243-263.

Benito G, Sancho C, Peña JL, Machado MJ, Rhodes EJ. 2010. Largescale karst subsidence and accelerated fluvial aggradation during MIS6 in NE Spain: climatic and paleohydrological implications. Quaternary Science Reviews 29: 2694-2704.

Burbank DW, Anderson RS. 2001. Tectonic Geomorphology. Blackwell Science: Oxford; 274.

Carbonel D, Rodríguez V, Gutiérrez F, McCalpin JP, Linares R, Roqué C, Zarroca M, Guerrero J. 2014. Sinkhole characterisation combining trenching, ground penetrating radar (GPR) and electrical resistivity tomography (ERT). Earth Surface Processes and Landforms 39: 214-227.

Carbonel D, Rodríguez-Tribaldos V, Gutiérrez F, Galve JP, Guerrero J, Zarroca M, Roqué C, Linares R, McCalpin JP, Acosta E. 2015. Investigating a damaging buried sinkhole cluster in an urban area integrating multiple techniques: geomorphological surveys, DInSAR, GPR, ERT, and trenching. Geomorphology 229: 3-16.

Caterina D, Beaujean J, Robert T, Nguyen F. 2013. A comparison study of image appraisal tools for electrical resistivity tomography. Near Surface Geophysics 11: 639-657.

Constable S, Parker RL, Constable CG. 1987. Occam's inversion: a practical algorithm for generating smooth models from electromagnetic sounding data. Geophysics 52: 289-300.

Dahlin T, Zhou B. 2004. A numerical comparison of 2D resistivity imaging with 10 electrode arrays. Geophysical Prospecting 52: 379-398.

Davis JL, Annan AP. 1986. High resolution sounding using ground probing radar. Geoscience Canada 13: 205-208.

De Giorgi L, Leucci G. 2014. Detection of hazardous cavities below a road using combined geophysical methods. Surveys in Geophysics 35: 1003-1021.

Fazzito S, Rapalini A, Cortés JM, Terrizzano CM. 2009. Characterization of Quaternary faults by electric resistivity tomography in the Andean Precordillera of Western Argentina. Journal of South American Earth Sciences 28: 217-228.

Festa V, Fiore A, Parise M, Siniscalchi A. 2012. Sinkhole evolution in the Apulian Karst of southern Italy: a case study, with some 
considerations on sinkhole hazards. Journal of Cave and Karst Studies 74: 137-147

Galve JP, Gutiérrez F, Lucha P, Bonachea J, Remondo J, Cendrero A Gutiérrez M, Gimeno M, Pardo G, Sánchez J. 2009. Sinkholes in the salt-bearing evaporite karst of the Ebro River valley upstream of Zaragoza city (NE Spain). Geomorphological mapping and analysis as a basis for risk management. Geomorphology 108: 145-158.

Griffiths DH, Barker RD. 1993. 2-Dimensional resistivity imaging and modeling in areas of complex geology. Journal of Applied Geophysics 29: 211-226.

Guerrero J, Gutiérrez F, Lucha P. 2008. Impact of halite dissolution subsidence on fluvial terrace development: case study of the Huerva River in the Ebro Basin (NE Spain). Geomorphology 100: 164-179.

Guerrero J, Gutiérrez F, Galve J. 2013. Large depressions, thickened terraces and gravitational deformation in the Ebro River valley (Zaragoza area, NE Spain). Evidence of glauberite and halite interstratal karstification. Geomorphology 196: 162-176.

Guinea A, Playà E, Rivero L, Himi M, Bosch R. 2010. Geoelectrical classification of gypsum rocks. Surveys in Geophysics 31: 557-580.

Gutiérrez F. 1996. Gypsum karstification induced subsidence: effects on alluvial systems and derived geohazards (Calatayud Graben, Iberian Range, Spain). Geomorphology 16: 277-293.

Gutiérrez F. 1998. Fenómenos de subsidencia por disolución de formaciones evaporíticas en las fosas neógenas de Teruel y Calatayud (Cordillera Ibérica), PhD Thesis. University of Zaragoza; 569.

Gutiérrez F, Arauzo T. 1997. Subsidencia kárstica sinsedimentaria en un sistema aluvial efímero: El Barranco de Torrecilla (Depresión del Ebro, Zaragoza). Cuadernos de Geología Ibérica 22: 349-372.

Gutiérrez M, Gutiérrez F. 1998. Geomorphology of the Tertiary gypsum formations in the Ebro Depression (Spain). Geoderma 87: 1-29.

Gutiérrez F, Cooper AH. 2013. In Surface morphology of gypsum karst. In Treatise on Geomorphology. Karst Geomorphology, Frumkin A (ed), Vol. 6. Elsevier: Amsterdam; 425-437.

Gutiérrez F, Guerrero J, Lucha P. 2008a. Quantitative sinkhole hazard assessment. A case study from the Ebro Valley evaporite alluvial karst (NE Spain). Natural Hazards 45: 211-233.

Gutiérrez F, Guerrero J, Lucha P. 2008b. A genetic classification of sinkholes illustrated from evaporite paleokarst exposures in Spain. Environmental Geology 53: 993-1006.

Gutiérrez F, Galve JP, Lucha P, Bonachea J, Jordá L, Jordá R. 2009. Investigation of a large collapse sinkhole affecting a multi-storey building by means of geophysics and the trenching technique (Zaragoza city, NE Spain). Environmental Geology 58: 1107-1122.

Gutiérrez F, Galve JP, Lucha P, Castañeda C, Bonachea J, Guerrero J. 2011. Integrating geomorphological mapping, trenching, InSAR and GPR for the identification and characterization of sinkholes in the mantled evaporite karst of the Ebro Valley (NE Spain). Geomorphology 134: 144-156.

Gutiérrez F, Parise M, De Waele J, Jourde H. 2014. A review on natural and human-induced geohazards and imapcts in karst. Earth Science Reviews 138: 61-88.

Kraus MJ. 1992. Alluvial response to differential subsidence: sedimentological analysis aided by remote sensing, Willwood Formation (Eocene), Bighorn Basin, Wyoming, USA. Sedimentology 39: 455-470.

Kraus MJ, Middleton LT. 1987. Dissected paleotopography and baselevel changes in a Triassic fluvial sequence. Geology 15: 18-21.

Kruse S, Grasmueck M, Weiss M, Viggiano D. 2006. Sinkhole structure imaging in covered karst terrain. Geophysical Research Letters 33: L16405.

LaBrecque D, Miletto M, Daily W, Ramirez A, Owen E. 1996. The effects of noise on Occam's inversion of resistivity tomography data. Geophysics 61: 538-548.

Leeder MR, Gawthorpe RL. 1987. Sedimentary models for extensional tilt-block/half-graben basins. In Continental Extensional Tectonics, Coward MP, Dewey JF, Hancock PL (eds) . Geological Society: London; 139-152.Geological Society Special Publications 28

Lewis CJ, McDonald EV, Sancho C, Peña JL, Rhodes EJ. 2009. Climatic implications of correlated Upper Pleistocene glacial and fluvial deposits on the Cinca and Gállego River (NE Spain) based on OSL dating and soil stratigraphy. Global and Planetary Change 67: 141-152.
Loke MH. 2011. Electrical resistivity surveys and data interpretation. In Solid Earth Geophysics Encyclopedia, 2nd Edition, Electrical \& Electromagnetic, Gupta H (ed). Springer-Verlag: Berlin; 276-283.

Loke MH. 2015. Tutorial: 2-D and 3-D electrical imaging surveys. Penang, Malaysia. http://www.geotomosoft.com/coursenotes.zip [June 2015].

Loke MH, Acworth I, Dahlin T. 2003. A comparison of smooth and blocky inversion method in $2 \mathrm{D}$ electrical tomography surveys. Exploration Geophysics 34: 182-187.

Luzón A, Pérez A, Soriano MA, Pocoví A. 2008. Sedimentary record of Pleistocene paleodoline evolution in the Ebro Basin (NE Spain). Sedimentary Geology 205: 1-13.

Miall AD. 1978. Lithofacies types and vertical profile models of braided river deposits: a summary. In Sedimentation and Tectonics in Alluvial Basins, Miall AD (ed) . Canadian Society of Petroleum Geology: Calgery; 597-604.Canadian Society of Petroleum Geology Memoir 5 Miall AD. 1985. Architectural-element analysis: a new method of facies analysis applied to fluvial deposits. Earth Science Reviews 22: 261-308.

Miall AD. 1996. The Geology of Fluvial Deposits. Sedimentary Facies, Basin Analysis, and Petroleum Geology. Springer: Berlin; 582.

Neal A. 2004. Ground Penetrating Radar and its use in sedimentology: principles, problems and progress. Earth-Science Reviews 66: 261-330.

Neal A, Richards J, Pye K. 2002. Structure and development of shell cheniers in Essex, southeast England, investigated using highfrequency ground-penetrating radar. Marine Geology 185: 435-469.

Nouioua I, Rouabhia A, Fehdi C, Boukelloul ML, Gadri L, Chabou D, Mouici R. 2013. The application of GPR and electrical resistivity tomography as useful tools in detection of sinkholes in the Cheria Basin (northeast of Algeria). Environmental Earth Sciences 68: 1661-1672.

Oldenborger GA, Routh PS, Knoll MD. 2007. Model reliability for 3D electrical resistivity tomography: application of the volume of investigation index to a time-lapse monitoring experiment. Geophysics 72: F167-F175.

Oldenburg DW, Li Y. 1999. Estimating depth of investigation in dc resistivity and IP surveys. Geophysics 64: 403-416.

Ouchi S. 1985. Response of alluvial rivers to slow active tectonic movement. Geological Society of America Bulletin 96: 504-515.

Pazdirek O, Blaha V. 1996. Examples of resistivity imaging using ME100 resistivity field acquisition system. Proceedings, EAGE 58th Conference and Technical Exhibition Extended Abstracts, Amsterdam.

Pellicer XM, Linares R, Gutiérrez F, Comas X, Roqué C, Carbonel D, Zarroca M, Rodríguez JAP. 2014. Morpho-stratigraphic characterization of a tufa mound complex in the Spanish Pyrenees using ground penetrating radar and trenching, implications for studies in Mars. Earth and Planetary Science Letters 388: 197-210.

Quirantes J. 1978. Estudio sedimentológico y estratigráfico del Terciario continental de los Monegros. Institución Fernando el Católico, CSIC: Zaragoza; 234

Rodríguez V, Gutiérrez F, Green AG, Carbonel D, Horstmeyer H, Schmelzbach C. 2014. Characterising sagging and collapse sinkholes in a mantled karst by means of Ground Penetrating Radar (GPR). Environmental and Engineering Geoscience 20: 109-132.

Salvany JM. 2009. Geología del yacimiento glauberítico de Montes de Torrero. Prensas Universitarias de Zaragoza: Zaragoza; 80.

Salvany JM, García-Veigas J, Ortí F. 2007. Glauberite-halite association of the Zaragoza Gypsum Formation (Lower Miocene, Ebro Basin, NE Spain). Sedimentology 54: 443-467.

Schumm SA. 1986. Alluvial river response to active tectonics. In Active Tectonics (Studies in Geophysics), Keller EA, Pinter N (eds). National Academy Press: New York; 80-94.

Schumm SA, Khan HR. 1972. Experimental study of channel patterns. Geological Society of America Bulletin 83: 1755-1770.

Smith DG, Jol HM. 1995. Ground penetrating radar: antenna frequencies and maximum probable depths of penetration in Quaternary sediments. Journal of Applied Geophysics 33: 93-100.

Suski B, Brocard G, Authemayou C, Muralles BC, Teyssier C, Holliger K. 2010. Localization and characterization of an active fault in an urbanized area in central Guatemala by means of geoelectrical imaging. Tectonophysics 480: 88-98.

Torrescusa S, Klimowitz J. 1990. Contribución al conocimiento de las evaporitas Miocenas (Fm. Zaragoza) de la Cuenca del Ebro. In 
Formaciones Evaporíticas de la Cuenca del Ebro, Cadenas Periféricas y de la Zona de Levante, Ortí F, Salvany JM (eds). Enresa: Barcelona; 120-123.

Urish DW. 1981. Electrical resistivity-hydraulic conductivity relationships in glacial outwash aquifers. Water Resources Research 17: 1401-1408.

Valero-Garcés BL, González-Sampériz P, Navas A, Machín J, DelgadoHuertas A, Peña-Monné JL, Sancho-Marcén C, Stevenson T, Davis B. 2004. Paleohydrological fluctuations and steppe vegetation during the last glacial maximum in the central Ebro valley (NE Spain). Quaternary International 122: 43-55.

Valois R, Camerlynck C, Dhemaied A, Guerin R, Hovhannissian G, Plagnes V, Rejiba F, Robain H. 2011. Assessment of doline geometry using geophysics on the Quercy plateau karst (south France). Earth Surface Processes and Landforms 36: 1183-1192.

van Dam RL, Schlager W. 2000. Identifying causes of groundpenetrating radar reflections using time-domain reflectometry and sedimentological analyses. Sedimentology 47: 435-449.

van den Berg JH. 1995. Prediction of alluvial channel pattern of perennial rivers. Geomorphology 12: 259-279.

van Schoor M. 2002. Detection of sinkholes using 2D electrical resistivity imaging. Journal of Applied Geophysics 50: 393-399.

Youssef AM, El-Kaliouby HM, Zabramawi YA. 2013. Integration of remote sensing and electrical resistivity methods in sinkhole investigation in Saudi Arabia. Journal of Applied Geophysics 87: 28-39.
Zarroca M, Bach J, Linares R, Pellicer XM. 2011. Electrical methods (VES and ERT) for identifying, mapping and monitoring different saline domains in a coastal plain region (Alt Empordà, northern Spain). Journal of Hydrology 409: 407-422.

Zarroca M, Linares R, Bach J, Roqué C, Moreno V, Font L, Baixeras C. 2012. Integrated geophysics and soil gas profiles as a tool to characterize active faults: the Amer fault example (Pyrenees, NE Spain). Environmental Earth Sciences 67: 889-910.

Zarroca M, Linares R, Rodellas V, Garcia-Orellana J, Roqué C, Bach J, Masqué P. 2014a. Delineating coastal groundwater discharge processes in a wetland area by means of electrical resistivity imaging, ${ }^{224} \mathrm{Ra}$ and ${ }^{222} \mathrm{Rn}$. Hydrological Processes 28: 2382-2395.

Zarroca M, Linares R, Roqué C, Rosell J, Gutiérrez F. 2014b. Integrated geophysical and morphostratigraphic approach to investigate a coseismic(?) translational slide responsible for the destruction of Montclús village (Spanish Pyrenees). Landslides 11: 655-671.

Zarroca M, Linares R, Velásquez-López PC, Roqué C, Rodríguez R. 2015. Application of electrical resistivity imaging (ERI) to a tailings dam project for artisanal and small-scale gold mining in Zaruma-Portovelo, Ecuador. Journal of Applied Geophysics 113: 103-113.

Zhou W, Beck BF, Adams AL. 2002. Effective electrode array in mapping karst hazards in electrical resistivity tomography. Environmental Geology 42: 922-928. 